\title{
Analysis of squalene and its transformation by-products in latent fingermarks by ultrahigh-performance liquid chromatography-high resolution accurate mass Orbitrap ${ }^{\mathrm{TM}}$ mass spectrometry
}

\author{
Buddhika N. Dorakumbura ${ }^{a, b \neq *}$, Francesco Busetti ${ }^{c}$ and Simon W. Lewis ${ }^{a, b}$ \\ a School of Molecular and Life Sciences, Curtin University, GPO Box U1987, Perth, Western Australia, \\ 6845, Australia. \\ ${ }^{b}$ Curtin Institute of Functional Molecules and Interfaces, Curtin University, GPO Box U1987, Perth, \\ Western Australia, 6845, Australia. \\ ' School of Science, Edith Cowan University, 270 Joondalup Drive, Joondalup, Western Australia, 6027, \\ Australia. \\ ‡ Present address: ChemCentre, PO Box 1250, Bentley, Western Australia, 6983, Australia. \\ *Author for correspondence (E-mail: buddhidk1013@gmail.com)
}

\section{Declarations of interest: None.}

\begin{abstract}
Transformation of squalene and its by-products in latent fingermarks over time under different storage conditions (light, dark, and underwater) was examined through ultrahigh-performance liquid chromatography-high resolution accurate mass Orbitrap $^{\mathrm{TM}}$ mass spectrometry. Complications of assessing fingermark compositional variation over time using multiple samples with varying initial compositions were elucidated and a more rational approach was successfully demonstrated. Squalene was detected in all fresh natural fingermarks deposited on non-porous surfaces and the amount ranged between 0.20 to $11.32 \mu \mathrm{g} / 5$ fingertips. A notable difference in the transformation of squalene was observed with different storage conditions, where a dark aquatic environment accelerated degradation of squalene compared to dark but dry conditions. Squalene monohydroperoxide was extremely short-lived in natural deposits while the amount of squalene epoxide was still increasing relative to the initial amount, after ageing under dark and aquatic conditions for up to 7 days. Some oxidation by-products of cholesterol were also tentatively identified, which exhibited a growth over time against their initial concentration under any of the storage condition tested. These by-products, therefore, show potential as biomarkers for targeted visualisation of aged deposits.
\end{abstract}

Keywords: Fingermark composition, degradation, squalene, by-products, high resolution accurate mass Orbitrap ${ }^{\mathrm{TM}}$ mass spectrometry 


\section{Introduction}

Successful recovery of latent fingermarks at crime scenes is critical to place individuals at the scene. The time elapsed from the deposition of the marks to the point of application of detection techniques often weakens the effectiveness of most of the current techniques. While some studies have been devoted to understanding the mechanisms of these methods to mitigate those limitations, ${ }^{1-5}$ several other studies have focused on developing novel techniques for the detection of aged deposits. ${ }^{6-12}$ One key approach in this direction is to identify relatively stable compounds in initial composition or transformation by-products in aged composition that pose suitable functional groups for targeted visualisation. In this context, there has been much interest in studying fingermark compositional variation over time using chromatographic techniques on both porous ${ }^{13-15}$ and non-porous substrates. ${ }^{6-7,9,16} \mathrm{An}$ ideal biomarker for targeted visualisation of aged deposits must be readily present in any deposit regardless of the donor characteristics and across a large population. Except one study, ${ }^{15}$ all other chromatographic investigations have identified squalene (SQ) as the single sebaceous compound, detected in abundance in almost every sample, even among an extensively large donor pool $(n=106){ }^{13-14,17-20}$ To this end, investigating squalene and its transformation by-products over time to identify molecular biomarkers as potential targets for fingermark visualisation is a rational approach.

Squalene is an unsaturated triterpene aliphatic hydrocarbon that participates as an intermediate product in the biosynthesis of cholesterol in the human body. ${ }^{21-22}$ It is found at significant levels only in sebaceous secretions and accounts for $10-15 \%$ of the total sebum lipids. ${ }^{23-27}$ The concentration of squalene in skin surface lipids is greater in areas such as the forehead, chest, and back, where there is high sebaceous gland activity. ${ }^{22}$ Squalene is incorporated into fingermark composition through habitual touching of body areas that are sebum-rich and also through the use of personal care products. ${ }^{28}$ Squalene in skin secretions undergoes decomposition into several oxygenated forms and breakdown products under different stressors such as ultraviolet (UV) radiation, environmental oxidants, and skin microflora. ${ }^{22}$ Investigations on human skin have identified squalene monohydroperoxide (SQ-OOH) as a primary oxidation by-product. ${ }^{29-32}$ Mountfort et al. studied the oxidation of squalene in solution with the presence and absence of a photo-oxidiser. ${ }^{6}$ They identified squalene hydroperoxides ranging from squalene dihydroperoxide $\left(\mathrm{SQ}-[\mathrm{OOH}]_{2}\right)$ to squalene pentahydroperoxide $\left(\mathrm{SQ}-[\mathrm{OOH}]_{5}\right)$ as a result of further oxidation of $\mathrm{SQ}-\mathrm{OOH}$. They were able to detect SQ- $[\mathrm{OOH}]_{4}$ and $\mathrm{SQ}-[\mathrm{OOH}]_{5}$ even after 20 days in solution in the absence of the photo-oxidizer and suggested these compounds could be potential targets for the visualisation of aged fingermarks. ${ }^{6}$

In addition, oxidation of squalene yields a series of isomers of squalene epoxide. ${ }^{6,33}$ In Mountfort's study, both SQ-OOH and SQ-epoxide were identified as readily formed but short-lived species, where 
SQ-OOH was rapidly oxidised to more highly substituted SQ hydroperoxides. ${ }^{6}$ Luca et al. identified four isomers of squalene epoxide and trans, trans-farnesal as another oxidation by-product of squalene. ${ }^{33}$ They emphasised on the difficulty of identification of squalene by-products due to the extreme reactivity and consequent short-lifespans of the intermediates. ${ }^{33}$ Photo-oxidation of squalene by exposure to UV irradiation can induce the formation of smaller volatile molecules such as formaldehyde, malonaldehyde, acetaldehyde, and acetone. ${ }^{34-35}$ Oxidation of squalene films under ozone was studied by Petrick and Dubowski where long-chain aldehydes and ketones were detected as surface products while formaldehyde, 4-oxopentanal, glyoxal, and pyruvic acid were recognised as volatile compounds. ${ }^{36}$

Some of these transformation by-products of squalene have been identified by chromatographic analysis of fingermark residue. ${ }^{6,15,19,37}$ Mong et al. speculated the presence of oxidation by-products of squalene in relatively fresh (1-day old) fingermarks, yet their presence was not confirmed by MS library comparison. ${ }^{15}$ One such suggestion was a cyclised product of squalene in the pathway of conversion to a steroid precursor. ${ }^{15}$ This product was observed in all samples in which squalene was abundant. Mountfort et al. were the first to carry out a preliminary study to identify oxidation by-products of squalene in fingermarks from one donor. ${ }^{6}$ Both SQ-OOH and SQ-epoxide were formed within 1 day in samples which were deposited on glass and aged under light conditions. These products were found to increase in concentration between 1 and 5 days after deposition. However, as SQ depleted from residues, both SQ-OOH and SQ-epoxide were barely detectable in 7-day old samples. ${ }^{6}$ In a GC-MS based analysis, Girod and Weyermann recently identified 6 oxidation by-products of squalene by examining the mass spectra and comparing with the oxidation products described by Petrick and Dubowski. ${ }^{36-37}$ Four of them; 6,10-dimethyl-5,9-undecadien-2-one (geranyl acetone), 5,9,13-trimethyl-tetradeca-4,8,12-triene-al (TTT), 4,8,13,17,21-tetra-methyl-octadeca-4,8,12,16,20pentaene-al (TOP), and 4,9,13,17-tetramethyl-octadeca-4,8,12,16-tetraeneal (TOT) were detected in all fresh residues deposited by 25 donors on glass microfiber filters. Two products, however, were identified as "possible" oxidation products as no confirmation could be made based on the literature. ${ }^{37}$ Based on their preliminary findings, Girod et al. further investigated ageing of these products (TTT, TOP, and TOT) with the intention of constructing ageing models for dating purposes with the use of chemometrics. ${ }^{19}$ Six lipid compounds were identified as major influential factors on the results, with four being squalene and related oxidation products (TTT, TOP, and TOT). The three oxidation products alone influenced discrimination of samples based on their age which were deposited on two separate months of a year, highlighting their significance to fingermark chemistry. Although the samples were aged up to about a month, the longevity of the oxidation products was not clearly presented as data 
interpretation was mainly focused on ageing models, but not necessarily on the stability of individual compounds. ${ }^{19}$

In early studies, oxidation products of skin surface lipids have been indirectly probed by thin layer chromatography, ${ }^{38}$ gas chromatography based techniques, ${ }^{26,33-35}$ and liquid chromatography coupled with chemiluminescence detection. ${ }^{39-40}$ In these investigations, the exact origin of the oxidation products was unclear. ${ }^{40}$ Gas chromatography based analysis often required derivatisation of samples to enable detection of polar oxidation products, ${ }^{26,33-35}$ which may induce unintended oxidation. ${ }^{6}$ While Girod and Weyermann identified few oxidation by-products of squalene using GC-MS without derivatisation, SQ-hydroperoxides were not identified. ${ }^{37}$ Mudiyanselage et al. and Mountfort et al. successfully demonstrated direct and simultaneous analysis of squalene and its oxidation products by liquid chromatography in conjunction with UV and MS detection. ${ }^{6,31}$

The work presented here describes application of ultrahigh-performance liquid chromatography-high resolution accurate mass Orbitrap $^{\mathrm{TM}}$ mass spectrometry (UHPLC-HRAM Orbitrap ${ }^{\mathrm{TM}}$ MS) for simultaneous and direct analysis of squalene and its transformation by-products formed in latent fingermarks due to different environmental conditions.

\section{Experimental}

\section{Chemicals}

Squalene ( $\geq 98 \%$; Sigma-Aldrich, USA), squalene- $d_{6}$ (98\%; Toronto Research Chemicals, Canada), acetonitrile (>99.9\%; VWR Chemicals, France), and dichloromethane ( $299.9 \%$; Honeywell Inc., USA) were used as received. Ultra-pure water used for laboratory purposes and the LC mobile phase was purified using an ion exchange system (IBIS Technology, Perth, Australia), followed by Elga Purelab Ultra System (High Wycombe, UK). A set of standard solutions of squalene was prepared in 1:1 v/v acetonitrile (ACN): dichloromethane (DCM) in the concentration range of 0.1-25.0 ppm $(0.1,1.0,4.5$, 12.0 , and $25.0 \mathrm{ppm}$ ). A standard solution of $20.0 \mathrm{ppm}$ squalene- $\mathrm{d}_{6}$ was also prepared in the same solvent mixture. All standard solutions were stored in amber glass vials wrapped in aluminium foil below $-18{ }^{\circ} \mathrm{C}$ to avoid degradation and solvent evaporation.

\section{Sample deposition}

\section{Monitoring degradation of squalene over time without knowing the initial composition}

Natural fingermarks were obtained from three donors (D1, D2, and D3) on the matt side of aluminium foil (heavy duty catering foil, Confoil, Australia) strips $\left(3 \times 9 \mathrm{~cm}^{2}\right)$ following the procedure outlined below. Donors were requested to wash their hands with liquid soap and warm water for about 2 minutes and allow them to air dry. Donors were then asked to engage in their regular activities for at least 30 minutes without washing hands or handling any food or chemicals before deposition. After 
rubbing hands together for 10 seconds, donors were requested to place one fingertip at a time on the aluminium strip, maintaining a constant contact area during deposition as much as possible. Deposition time was 10 seconds in all cases. Donors placed five fingertips from one hand which was considered as one sample. Another sample from the other hand was obtained at the same time and these two samples were considered as duplicate samples. A maximum of three sample sets were collected from each donor within the course of a working day (9.00 am to $5.00 \mathrm{pm}$ ) maintaining at least 30 minutes time interval between each sampling time. This procedure was repeated throughout a week. Demographics of the donors are given in Table 1.

To investigate the influence of the fingermark matrix over the degradation process, three $10 \mu \mathrm{L}$ aliquots of $50.0 \mathrm{ppm}$ squalene standard were deposited as three separate spots on an aluminium strip. Eight strips were prepared in a similar fashion.

\section{Monitoring degradation of squalene over time with known initial composition}

Natural fingermarks were obtained from three donors (D1, D2, and D4) on aluminium foil strips as outlined earlier with controlled deposition force. An aluminium foil strip was placed on a kitchen scale (Soehnle, Germany) where the top surface of the scale was covered with aluminium foil to prevent contamination. After rubbing hands together, donors were requested to place one fingertip at a time on the aluminium strip while maintaining the reading of the scale at $500 \pm 100 \mathrm{~g}$ during deposition. Two samples from both hands were obtained (one set of samples) and three such sets were obtained from each donor per each storage condition. This procedure was repeated over two consecutive weeks to obtain nine sample sets from each donor ( 54 samples in total, 18 samples per donor $\mathrm{x} 3$ donors). Further sampling was not carried out due to limitations with time and resources. Recent use of cosmetics, personal care products (moisturisers, haircare products, and hand and body lotions), and nutritional supplements by donors were recorded at each sampling time (Table 1).

Table 1. Demographics of the donors.

\begin{tabular}{cccc}
\hline Donor & $\begin{array}{c}\text { Age } \\
\text { (years) }\end{array}$ & Biological sex & Cosmetic use \\
\hline D1 & 33 & Female & $\begin{array}{c}\text { Regular use of moisturiser, cosmetics, hair oil } \\
\text { and hand cream. Daily consumes fish oil as a } \\
\text { nutritional supplement }\end{array}$ \\
\hline D2 & 26 & Male & Intermittent use of moisturiser and haircare \\
products
\end{tabular}




\section{Sample storage}

All samples, except those that were extracted within 5 hours following deposition (i.e., $t=0$-day samples), were stored under three different storage conditions: light, dark, and underwater in dark. Details of these conditions are listed in Table 2. Before storing samples under light or dark conditions, aluminium substrates were slightly rolled at one end and then inserted approximately $2 \mathrm{~cm}$ of that end into $20 \mathrm{~mL}$ glass vials (Gerresheimer, Germany) (Supplementary Information Figure S1).

Table 2. Different storage conditions used to store samples.

\begin{tabular}{cc}
\hline $\begin{array}{c}\text { Storage under } \\
\text { light conditions }\end{array}$ & $\begin{array}{c}\text { Vials were stored vertically in an office environment at room } \\
\text { temperature }\left(21-23^{\circ} \mathrm{C}\right) \text { where samples were exposed to diurnal light } \\
\text { cycle. }\end{array}$ \\
\hline $\begin{array}{c}\text { Storage under } \\
\text { dark conditions }\end{array}$ & $\begin{array}{r}\text { Vials were placed vertically inside a cardboard box and covered with } \\
\text { its lid such that samples were exposed to complete darkness. The } \\
\text { sample box was kept in an office environment at room temperature } \\
\left(21-23^{\circ} \mathrm{C}\right) .\end{array}$ \\
\hline $\begin{array}{c}\text { Storage } \\
\text { underwater }\end{array}$ & $\begin{array}{c}\text { Aluminium strips were submerged in a water bath filled with tap } \\
\text { water. Clean glass slides were placed at the corners of strips avoiding } \\
\text { contact with the deposits to prevent the strips floating on the surface. } \\
\text { The water baths were completely covered with aluminium foil to } \\
\text { prevent exposure to light. }\end{array}$ \\
\hline
\end{tabular}

\section{Sample preparation}

\section{Monitoring degradation of squalene over time without knowing the initial composition}

One sample set per donor was extracted on the same day of deposition (i.e., $\mathrm{t}=0$-day samples) and others were aged under the pre-determined storage conditions. The analysis time intervals were $t=1$ and $\mathrm{t}=5$-days. After ageing, they were extracted and analysed in duplicate as below: Aluminium strips were rolled and inserted into $4 \mathrm{~mL}$ glass screw-top extraction vials (Grace Davison Discovery Sciences, Australia), which were pre-rinsed with DCM. A volume of $0.7 \mathrm{~mL}$ of 1:1 v/v ACN/DCM was added, and vials were screw capped using matching caps lined with polytetrafluoroethylene. Vials were wrapped in aluminium foil to avoid exposure to light during sample extraction. They were placed in an ultrasonic bath (Soniclean, Australia) which was kept on an orbital shaker (Ratek, Australia) with mild agitation for 10 minutes. The individual vials were then vortex mixed (Ratek, Australia) for 2 minutes. Sample extracts were transferred to $2 \mathrm{~mL}$ amber glass autosampler vials (Agilent Technologies, USA) and sealed with matching polytetrafluoroethylene/silicon bonded screw caps. Sample blanks were prepared using aluminium foil strips bearing no deposits.

Aluminium strips bearing standard spots of squalene were aged up to 1 day under the same storage conditions and analysed in duplicate. The extraction procedure was the same as mentioned above. 


\section{Monitoring degradation of squalene over time with known initial composition}

One sample of a given set (i.e., a sample from one hand) was extracted within 5 hours since deposition. The remaining sample (i.e., the sample from the other hand) was extracted after ageing under a selected storage condition (light or dark or underwater) up to the desired time interval ( 1 or 5 or 7 days). Aluminium strips were rolled and inserted into $4 \mathrm{~mL}$ clear glass vials. Samples aged underwater were air dried on paper towels in dark for 5 to 10 minutes before inserting into extraction vials. Then $0.6 \mathrm{~mL}$ of $1: 1 \mathrm{v} / \mathrm{v}$ ACN:DCM was added followed by $0.1 \mathrm{~mL}$ of the $20.0 \mathrm{ppm}$ squalene- $\mathrm{d}_{6}$ surrogate standard. Samples were extracted by sonication and vortex mixing as mentioned earlier. The extracts were transferred to amber autosampler vials and sealed.

\section{Chemical analysis}

Squalene and other species in latent fingermarks were analysed by using a Dionex Thermofisher Ultimate 3000 UHPLC system coupled to a Q-Exactive Focus Thermofisher Orbitrap ${ }^{\mathrm{TM}}$ mass spectrometer via an APCl ion source operated in positive ion mode. The chromatography and mass spectrometry parameters were adapted from the work reported by Mountfort et al. ${ }^{6}$ to accommodate the use of different equipment. The UHPLC system was equipped with a solvent degasser unit, a binary pump, and a 120 well-plate autosampler. The injection volume was 5 to $10 \mu \mathrm{L}$. An Acquity C18 column (Waters USA, $2.1 \times 100 \mathrm{~mm}, 1.7 \mu \mathrm{m}$ particle size) was used for the separation of compounds. A mobilephase gradient was employed as follows: $1: 1 \mathrm{v} / \mathrm{v}$ ACN/ $\mathrm{H}_{2} \mathrm{O}$ for $10 \mathrm{~min}$, then increased to $100 \% \mathrm{ACN}$ up to $20 \mathrm{~min}$ and held at that up to $25 \mathrm{~min}$, and then re-equilibrated for 5 minutes at the initial conditions. A flow rate of $0.4 \mathrm{~mL} / \mathrm{min}$ was maintained throughout the chromatographic run. MS conditions are listed in Table 3. 
Table 3. $\mathrm{APCl}(+)$ and $\mathrm{MS}$ tuning parameters used for the detection of squalene and its transformation by-products.

\begin{tabular}{|c|c|}
\hline APCl-Orbitrap $^{\mathrm{TM}}$ MS parameters & Setting \\
\hline Vaporization temperature & $375^{\circ} \mathrm{C}$ \\
\hline Spray voltage & $5 \mathrm{kV}$ \\
\hline Sheath gas flow rate & 30 (arbitrary units) \\
\hline Aux/sweep gas flow rate & 5/0 (arbitrary units) \\
\hline Discharge current & $4.5 \mu \mathrm{A}$ \\
\hline Capillary temperature & $237.5^{\circ} \mathrm{C}$ \\
\hline RF lenses & $70 \mathrm{~V}$ \\
\hline AGC target $10^{6}$ & MS Scan \\
\hline AGC target $5 e^{4}$ & $\mathrm{MS} / \mathrm{MS}$ \\
\hline Max injection time & auto \\
\hline Dynamic exclusion & auto \\
\hline Collision Energy & $30 \mathrm{eV}$ \\
\hline MS acquisition mode & $\begin{array}{c}\text { Full scan (70-1000 amu @70K resolution) + } \\
\text { ddHRMS² (@17.5K resolution) in "discovery } \\
\text { mode" }\end{array}$ \\
\hline
\end{tabular}

\section{Data analysis}

Identification and quantification of squalene and potential transformation by-products were performed using Xcalibur QualBrowser 4.0.27.13 and TraceFinder 4.2 software from Thermo-Fisher. For the identification of unknown transformation by-products, the $m / z$ ratio of potential peaks was identified using the "ion map" function in Xcalibur, which plots retention time vs $m / z$ vs peak intensities (Figure 1). In addition to this, the $\mathrm{m} / \mathrm{z}$ values corresponding to the most intense hundred peaks were also extracted from the chromatographic traces and evaluated against sample blanks. The $m / z$ ratio of positively identified peaks was used as the base peak $\mathrm{m} / \mathrm{z}$ to confirm the presence of the particular compound with a mass tolerance of $5 \mathrm{ppm}$ and a mass precision of 4 decimal places. Measured $\mathrm{m} / \mathrm{z}$ ratios of the positive peaks were then used to generate molecular formulas where measured mass and the isotope pattern were compared against the theoretical mass of the predicted compound (with a relative error $<5 \mathrm{ppm}$ ) and the simulated isotope pattern. When possible, $\mathrm{MS}^{2}$ spectra were also used to confirm the structure of the newly identified transformation by-products. 
Absolute quantitation of squalene was performed using the ratio of the peak areas of the analyte and of the deuterated standard by using the quantitation software package TraceFinder 4.2. Relative quantification of by-products was performed by normalising the peak area of the by-product to that of the deuterated standard.

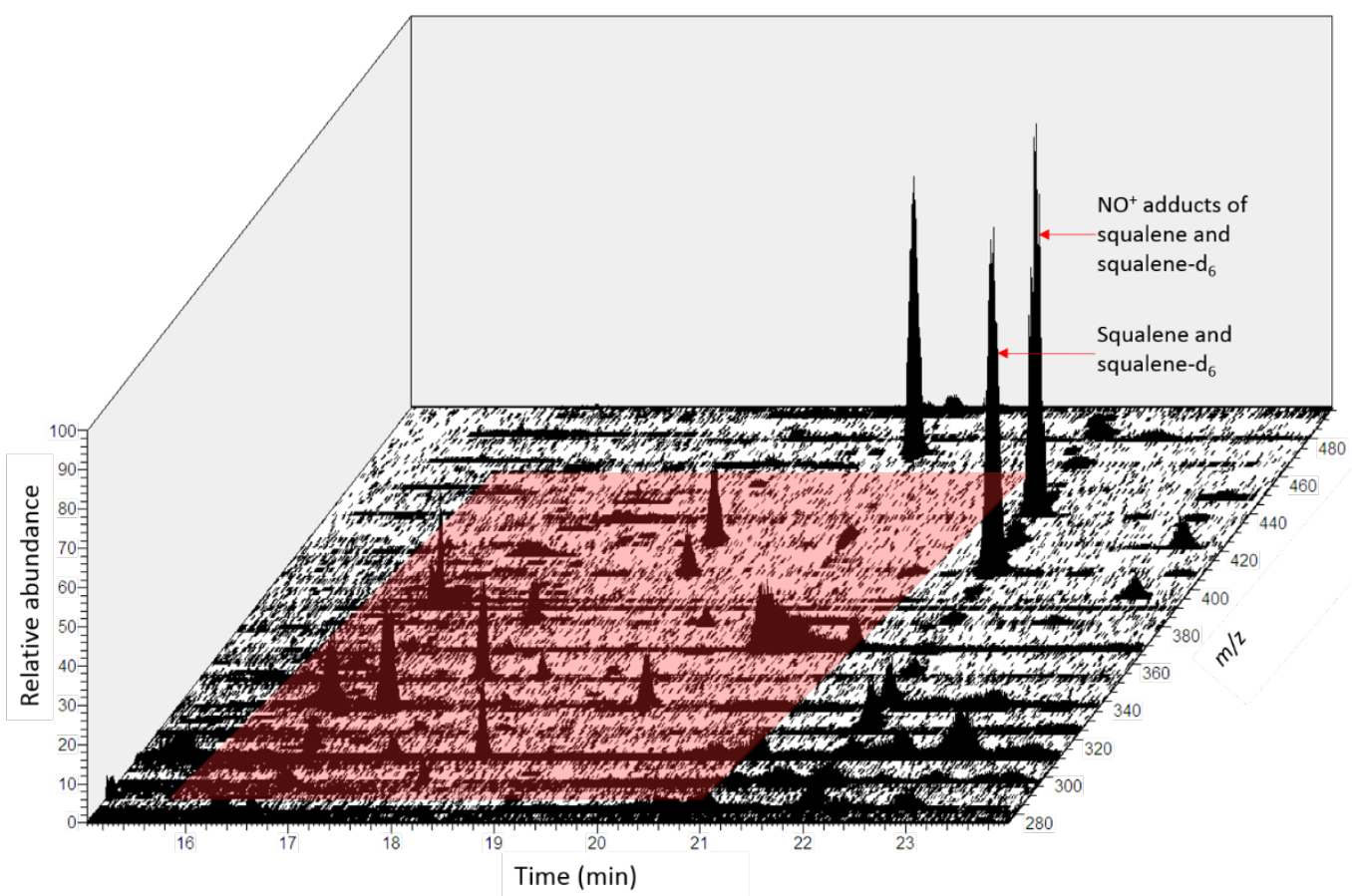

Figure 1. A sample ion map showing squalene, squalene- $\mathrm{d}_{6}$, and the degradation by-products (in the red shaded area) identified in the study.

\section{Results and discussion}

\section{Preliminary considerations}

The extraction procedure and the conditions for the chromatographic separation reported by Mountfort et al. were used as a starting point for this study. ${ }^{6}$ Initially, suitability of ACN, DCM, and $1: 1 \mathrm{v} / \mathrm{V} \mathrm{ACN} / \mathrm{DCM}$ as the extraction solvent was investigated. Extraction was initially carried out with $0.7 \mathrm{~mL}$ of the extraction solvent in $1.75 \mathrm{~mL}$ vials. The recovery of squalene using ACN and DCM was $56 \%$ and $104 \%$ respectively. Although Mountfort et al. used ACN for their sample extraction $(150 \mu \mathrm{L}){ }^{6}$ in the present study, it was observed that squalene was immiscible in ACN. Despite the improved recovery of squalene with $\mathrm{DCM}, 100 \% \mathrm{DCM}$ caused peak fronting. This is due to disturbance caused to the mobile phase equilibrium in the column as the mobile phase composition was $A C N / \mathrm{H}_{2} \mathrm{O} .{ }^{41}$ The third solvent combination of $1: 1 \mathrm{v} / \mathrm{V}$ ACN/DCM yielded a recovery of only $26 \%$. Nonetheless, when the same solvent combination was used in a $4 \mathrm{~mL}$ extraction vial, a recovery of $113 \%$ was achieved. These results suggest that the correct size of the extraction vial was important to achieve optimal extraction. The aluminium foil was tightly packed inside the small $1.75 \mathrm{~mL}$ vial, which impeded proper contact between the solvent and the sample, leading to incomplete extraction. 


\section{Degradation of squalene over time}

\section{Without knowing the initial composition}

Although previous chromatographic studies have detected squalene in abundance in fresh fingermarks, they have used charged deposits except for Croxton and co-workers. ${ }^{16}$ While Mountfort et al. investigated oxidation by-products in aged fingermarks for the identification of potential biomarkers, ${ }^{6}$ results of this study may not represent real-life aged samples due to the use of charged deposits. To this end, this study, for the first time, investigated the transformation of squalene in natural fingermarks deposited on non-porous surfaces.

Figure 2 demonstrates the compositional variation of squalene in duplicate samples obtained from both hands and squalene standard spots deposited on aluminium foil which were aged under different storage conditions. It should be noted here that the luminosity of the office environment used to store the fingermark samples in this study was not measured. Hence, the "light condition" discussed in this article resembles an office space which was exposed to fluorescent bulbs for more than 8 hours of the day and natural light during the daytime. Degradation of squalene in fingermarks aged under light condition followed the same trend as the standard spots. The most likely degradation pathway is via oxidation. Mountfort et al. reported a series of oxidation by-products of squalene that were detected in solution in the presence of a photo-oxidizer. ${ }^{6}$ However, the fate of squalene was not clear in other storage conditions. The average amounts of squalene in final extracts $(0.7 \mathrm{~mL})$ of samples aged under dark and dark underwater conditions from both donors D1 and D2 increased after 1 day while the standard spots displayed a reduction. As squalene is highly sensitive to photo- and air-oxidation, this result could be due to following reasons: (i) There could be reactions taking place within the residue that contribute to generation of squalene with time ${ }^{15}$ or (ii) the aged samples initially had high amounts of squalene hence the reduction over time was not prominent against the "initial composition" (i.e., another sample set with a different amount of squalene, obtained at a different time). As emphasised in our previous article, ${ }^{42}$ the intra-donor variability is a key issue in fingermark research which may have predominantly contributed to these results..$^{15,17-18,20}$ 


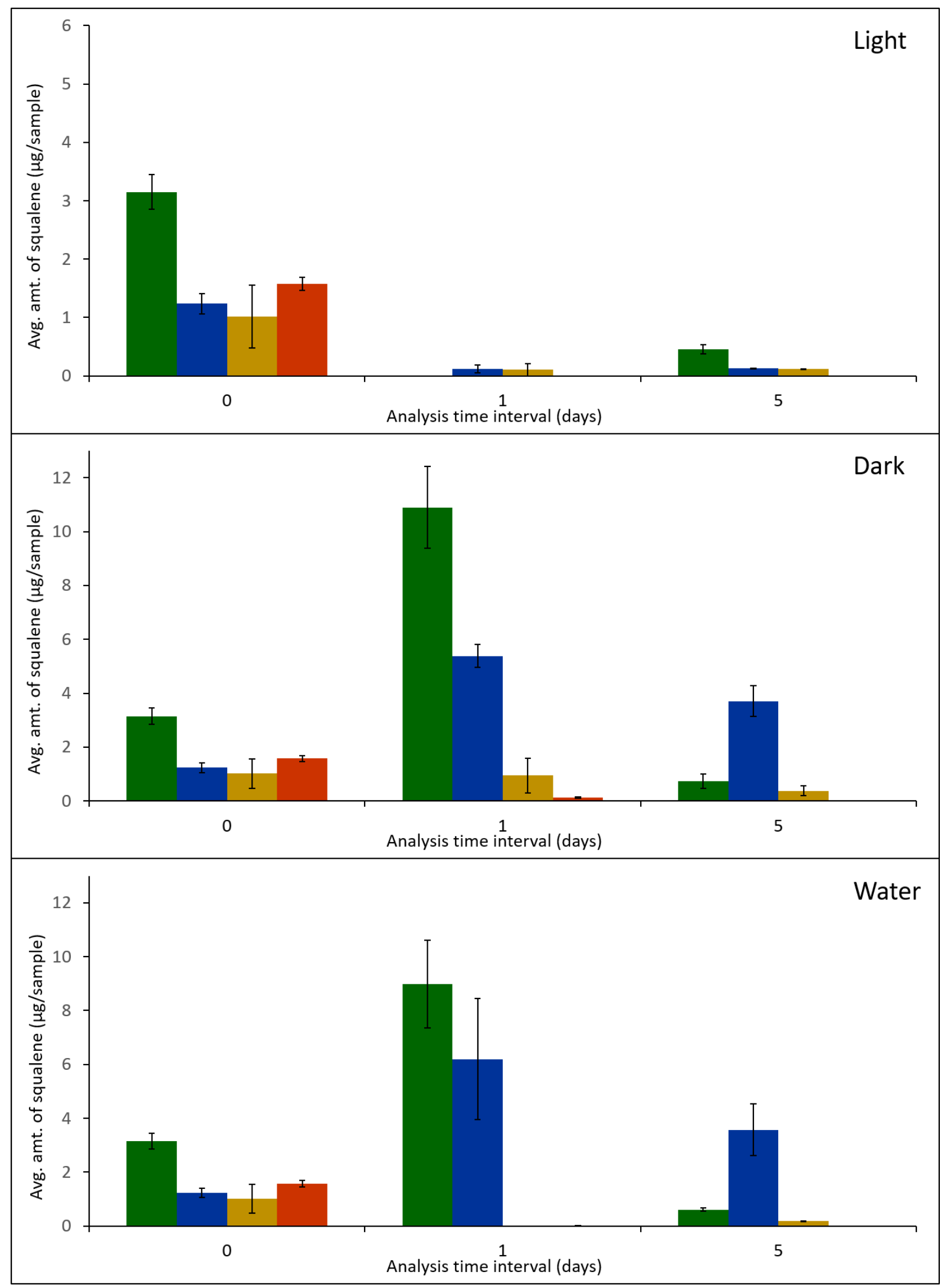

Figure 2. Degradation of squalene over time ( $t=0,1$, and 5 days) in fingermarks and in standard spots deposited on aluminium foil. Each bar represents the average value of duplicate samples obtained from both hands (two foil strips in the case of standard spots). Data for donor D1 is in green, D2 in blue, D3 in brown, and standard spots in red. The error bars represent the range of the duplicate samples. Standard spots were aged only up to one day. 


\section{With known initial composition}

The practical difficulty of comparing fingermark composition over time using destructive techniques has been highlighted in previous studies. ${ }^{13,15,17}$ Yet, the approach undertaken in the previous section has been widely employed throughout fingermark research due to limitations of other techniques. $^{6-7,13,15,18}$ While these studies have greatly contributed to current understanding of fingermark composition, this approach may have confounded the identification of potential trends of the degradation of fingermark components. As such, we previously carried out an investigation to identify a sampling approach that produces least compositional variation between two fingermark samples deposited at a given time ${ }^{42}$ This approach allows to extract and analyse one sample to know the initial composition and to age the remainder (See Supplementary Information Figure S2).

As shown in Figure 3, squalene was detected in all samples that were analysed for initial composition and was within a range of 0.20 to $11.32 \mu \mathrm{g} / \mathrm{sample}$. It should be noted here that, according to the findings of our previous work, ${ }^{42}$ the homogeneity of samples obtained from both hands (by following the Sampling Protocol 4 outlined previously ${ }^{42}$ ) at a time with respect to the amount of squalene is subjected to a percentage difference of approximately $20 \%$. This means that each initial composition and the corresponding initial composition of the aged sample can be different from each other by approximately $20 \%$. Presumably, largely due to this variability, the fate of squalene after ageing for 1 day under light conditions was not conclusive. Only the donor D2 showed a $22 \%$ reduction from the initial amount of squalene while donors D1 and D4 showed a $66 \%$ and 102\% increase respectively. However, a clear reduction of the amount of squalene in 5-day and 7-day old samples from all donors was visible in Figure 3.

In contrast to the standard spots mentioned in the previous section where squalene was not detected (LOD $0.09 \mu \mathrm{g} / \mathrm{mL}$ and LOQ $0.30 \mu \mathrm{g} / \mathrm{mL}$ ) in 1-day old samples under any storage condition, squalene was detected in aged fingermarks, especially $\mathrm{t}=1$ and 5-day old samples stored under dark and underwater. This suggests the complex fingermark matrix consisting of several endogenous and exogeneous species influences the degradation process. 

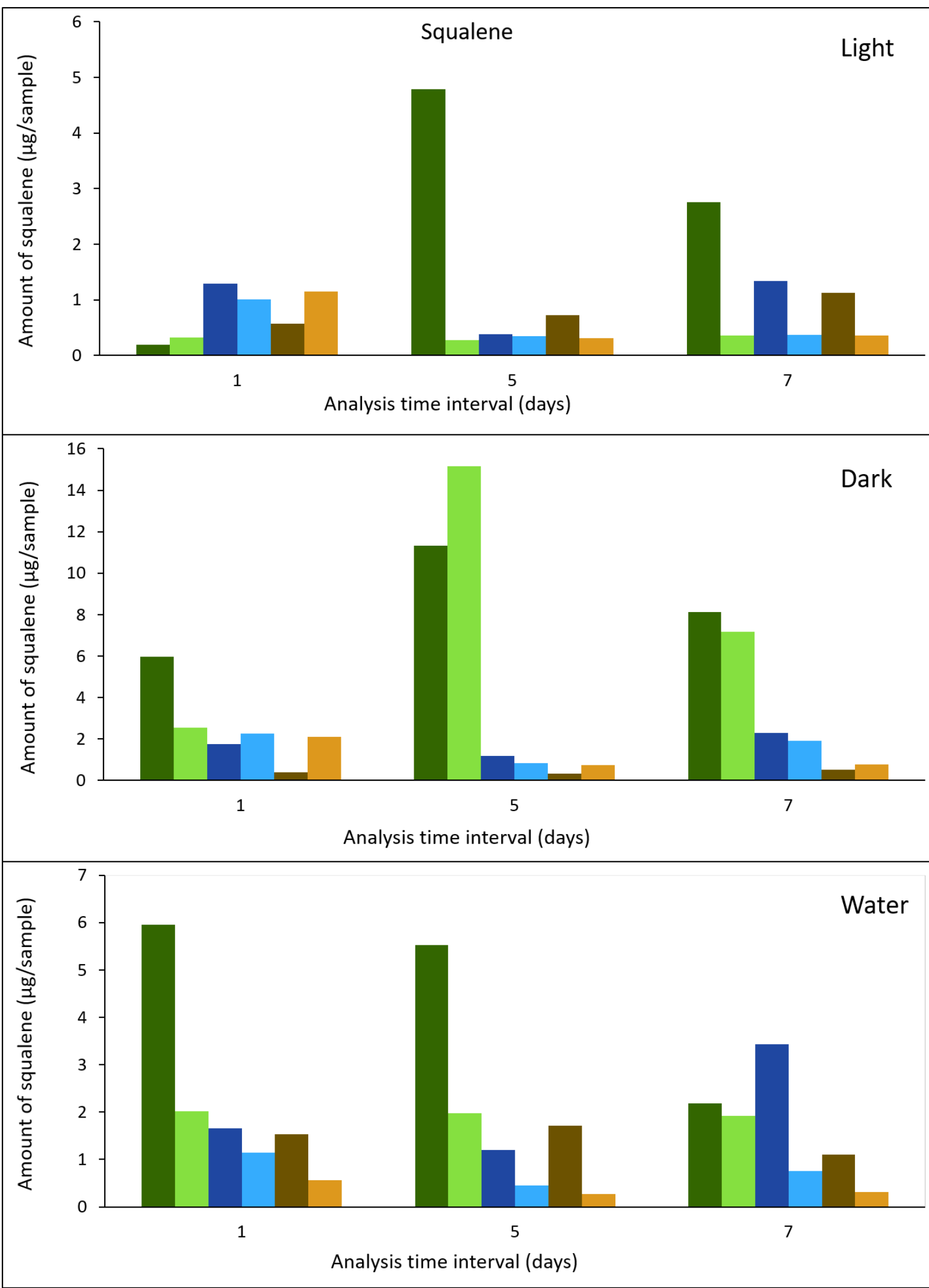

Figure 3. Degradation of squalene over time (1,5, and 7 days) in fingermarks in relation to their initial composition. Data for donor D1 is presented in green, D2 in blue, and D4 in brown. Each darker colour bar represents initial composition and lighter colour bar represents corresponding aged composition. A 'sample' denotes fingermarks obtained from five fingers from one hand. 
In Mountfort's study, oxidation of squalene was faster in fingermarks than in standard solutions (in vitro) because of approximately 100-fold higher starting concentration of squalene in solution. ${ }^{6}$ Based on our preliminary findings, the amount of squalene deposited on a foil strip (approximately $1.5 \mu \mathrm{g}$ ) was chosen to be comparable to the amount in natural fingermarks on the same substrate. Hence, the faster degradation rate of standard spots may be also due to differences in the morphology of fingermarks and spots. Fingermarks are comprised of small droplets of material while standard spots are not. Using synchrotron sourced Fourier transform infrared and confocal Raman microscopy, we have previously demonstrated that depending on the lipid-to-eccrine material ratio within droplets, lipids may co-exist in aqueous droplets as an emulsion. ${ }^{43}$ The observed slower degradation rate of squalene in fingermarks consequently could be a result of this complex spatial distribution of material within droplets.

The degradation rate of squalene in the dark was much slower than that under light conditions. All three donors showed a greater than $69 \%$ reduction of the initial amount of squalene after ageing for 7 days under light, while two of three donors exhibited a lower than $17 \%$ reduction after ageing for the same period under dark. In the study reported by Archer et al. where charged fingermarks were deposited on filter paper, squalene was detectable in some samples even after 33 days when they were stored in dark. ${ }^{13}$ Considering the number of digits deposited per sample in their study (1.5 digits in contrast to 5 digits in this study), the greater longevity of squalene in Archer's study can be attributed to the effect of substrate porosity and the type of the deposits (charged vs natural) analysed. To the best of our knowledge, transformation of squalene in latent fingermarks stored underwater has not been investigated before. In forensic investigations, wetted surfaces are known to be challenging surfaces on which to develop fingermarks. ${ }^{44}$ Studies have found the small particle reagent (SPR) technique to be more effective (if the articles are developed without leaving them air-dry) in this regard among other popular techniques applied on non-porous surfaces. ${ }^{44-46}$ This technique involves a surfactant and a suspension material where the enhancement is achieved upon the interactions formed between fatty components of the residue and hydrophobic tails of the surfactant. ${ }^{46-48}$ To this end, investigation of the degradation of lipid molecules underwater is of high significance.

Squalene degraded in all samples when they were stored underwater (Figure 3). The percentage reduction of squalene from the initial concentration for donors D1, D2, and D4 were $66 \%, 31 \%$, and $63 \%$ for $\mathrm{t}=1$-day samples; $64 \%, 62 \%$, and $84 \%$ for $\mathrm{t}=5$-day samples; and $12 \%, 78 \%$, and $71 \%$ for $\mathrm{t}=7$-day samples respectively. In a comparison of percentage reduction of $t=7$-day samples aged underwater to that of under dark conditions, relatively higher percentages were observed for underwater conditions. As the water baths containing samples were covered with foil to avoid exposure to light, this result suggests that water alone has accelerated the degradation process. This could be due to the 
removal of water-soluble eccrine material from the fingermark droplets which increased the surface area of lipids to interact with dissolved oxygen in water. It was previously thought that hydrophobic fingermark lipid compounds are preserved under aquatic environments compared to dry conditions, ${ }^{5}$ thus they could be targeted for the visualisation of fingermarks on items recovered from aquatic environments. However, according to the results of this study, aquatic conditions are indirectly detrimental to the major hydrophobic lipid compound in fingermarks; squalene.

\section{Identification of transformation by-products}

A range of transformation by-products were identified using high resolution accurate mass Orbitrap ${ }^{\mathrm{TM}}$ mass spectrometry, including oxidation by-products of $\mathrm{SQ}$ and cholesterol (CHOL). Identification based on precursor ions of SQ and most of its oxidation products was performed as per results reported by Mountfort et al. ${ }^{6}$ The relative quantification of SQ-OOH and SQ-epoxide was based on the precursor ions at $\mathrm{m} / \mathrm{z} 425.3780$ and 427.3938 respectively. The presence of 4,9,13,17-tetramethyl-octadeca$4,8,12,16$-tetraeneal (TOT) was confirmed based on the ozonolysis mechanism of SQ proposed by Petrick and Dobowski, ${ }^{36}$ and detection of this compound in fingermarks using GC-MS by Girod and Weyermann. ${ }^{37}$ Oxidation is likely to introduce epoxide, $-\mathrm{OH},-\mathrm{OOH}$, and aldehyde/keto groups to SQ which are all well ionised in $\mathrm{APCl}(+)$, although some rearrangements of squalene by-products are also possible following oxidation. Since APCI (+) ion mode yielded a satisfactory ionisation coverage of the by-products that are likely to form from the oxidation of squalene, further investigations using $\mathrm{APCl}(-)$ ion mode was not carried out. Positive identification of cholesterol in the sample extracts was confirmed through the following: (i) the mass accuracy of the observed precursor ion $\mathrm{m} / \mathrm{z} 369.3519$ was less than $3 \mathrm{ppm}$ from the theoretical $m / z$ ratio of $\left[(\mathrm{M}+\mathrm{H})-\mathrm{H}_{2} \mathrm{O}\right]^{+}$(correct elemental formula $\mathrm{C}_{27} \mathrm{H}_{45}$, $\mathrm{m} / \mathrm{z}$ 369.3516), (ii) comparison of $\mathrm{MS}^{2}$ spectra against NIST MS/MS library (80\% match), and (iii) comparison of the isotopes distribution of the monitored ion against the simulated HRAM spectra of $\mathrm{C}_{27} \mathrm{H}_{45}$ (Supplementary Information Figure S3 and S4). Cholesterol oxidation products were identified based on the study reported by Raith et al. where five oxidation products were identified in meat by liquid chromatography-atmospheric pressure chemical ionisation/mass spectrometry (LC-APCI/MS) ${ }^{49}$ Target products (TPs) detected only in samples from donor D1 that did not show any correlation to the available amount of SQ were not further assigned, assuming that they were of exogenous origin or not derived from SQ. Compound eluted at 17.55 min were attributed to $[\mathrm{M}+\mathrm{H}]^{+}$ion of $\mathrm{C}_{19} \mathrm{H}_{34} \mathrm{O}_{4}$ based on previous HRAM studies. ${ }^{50-51}$ Table 4 shows precursor ions used for compound identification and the ion map in Figure 1 shows all the degradation products detected. 
Table 4. Compound identification based on precursor ions in the mass spectra using the established UHPLC-APCI/HRAM Orbitrap ${ }^{\mathrm{TM}} \mathrm{MS}$.

\begin{tabular}{|c|c|c|c|c|c|}
\hline $\begin{array}{c}m / z \text { of } \\
\text { precursor } \\
\text { ion }\end{array}$ & $\begin{array}{l}\text { Retention } \\
\text { time } \\
\text { (min) }\end{array}$ & $\begin{array}{l}\text { Precursor ion } \\
\text { (monitored } \\
\text { ion) }\end{array}$ & $\begin{array}{c}\text { Molecular } \\
\text { formula of } \\
\text { the } \\
\text { precursor }\end{array}$ & $\begin{array}{l}m / z \\
\text { error } \\
(\mathrm{ppm})\end{array}$ & $\begin{array}{c}\text { Tentative } \\
\text { assignment/ } \\
\text { comment }\end{array}$ \\
\hline 207.1017 & 20.29 & & $\mathrm{C}_{12} \mathrm{H}_{15} \mathrm{O}_{3}$ & $<1.3$ & Only in D1F1 \\
\hline 257.2476 & 16.61 & & $\mathrm{C}_{16} \mathrm{H}_{33} \mathrm{O}_{2}$ & $<1.6$ & Only in D1F1 \\
\hline 312.3263 & 17.54 & & $\mathrm{C}_{20} \mathrm{H}_{42} \mathrm{ON}$ & $<1.9$ & $\begin{array}{l}\text { Not } \\
\text { prominent in } \\
\text { aged samples }\end{array}$ \\
\hline 313.3103 & 18.36 & & $\mathrm{C}_{20} \mathrm{H}_{41} \mathrm{O}_{2}$ & $<1.5$ & Only in D1F1 \\
\hline 317.2841 & 16.66 & {$[\mathrm{M}+\mathrm{H}]^{+}$} & $\mathrm{C}_{22} \mathrm{H}_{37} \mathrm{O}$ & $<1.9$ & TOT \\
\hline 327.2534 & 17.55 & {$[\mathrm{M}+\mathrm{H}]^{+}$} & $\mathrm{C}_{19} \mathrm{H}_{35} \mathrm{O}_{4}$ & $<1.7$ & $\mathrm{C}_{19} \mathrm{H}_{34} \mathrm{O}_{4}$ \\
\hline 355.2845 & $\begin{array}{l}17.77- \\
20.18\end{array}$ & & $\mathrm{C}_{21} \mathrm{H}_{39} \mathrm{O}_{4}$ & $<1.7$ & Only in D1F1 \\
\hline 367.3360 & 17.85 & {$\left[(\mathrm{M}+\mathrm{H})-2 \mathrm{H}_{2} \mathrm{O}\right]^{+}$} & $\mathrm{C}_{27} \mathrm{H}_{43}$ & $<1.5$ & $\begin{array}{c}\text { Cholesterol } \\
\text { oxidation } \\
\text { products } \\
\text { (COPs) }\end{array}$ \\
\hline 369.3519 & 20.33 & {$\left[(\mathrm{M}+\mathrm{H})-\mathrm{H}_{2} \mathrm{O}\right]^{+}$} & $\mathrm{C}_{27} \mathrm{H}_{45}$ & $<2.5$ & $\mathrm{CHOL}$ \\
\hline 385.3468 & 18.85 & {$[\mathrm{M}+\mathrm{H}]^{+}$} & $\mathrm{C}_{27} \mathrm{H}_{45} \mathrm{O}$ & $<1.1$ & $\begin{array}{l}\text { Cholesterol } \\
\text { oxidation } \\
\text { products }\end{array}$ \\
\hline \multirow[t]{2}{*}{409.3832} & \multirow[t]{2}{*}{18.99} & {$\left[(\mathrm{M}+\mathrm{H})-\mathrm{H}_{2} \mathrm{O}_{2}\right]^{+}$} & \multirow[t]{2}{*}{$\mathrm{C}_{30} \mathrm{H}_{49}$} & \multirow[t]{2}{*}{$<1.7$} & $\mathrm{SQ}-\mathrm{OOH}$ \\
\hline & & {$\left[(\mathrm{M}+\mathrm{H})-\mathrm{H}_{2} \mathrm{O}\right]^{+}$} & & & SQ-epoxide \\
\hline 411.3988 & 21.95 & {$[\mathrm{M}+\mathrm{H}]^{+}$} & $\mathrm{C}_{30} \mathrm{H}_{51}$ & $<0.8$ & SQ \\
\hline 417.4665 & 21.85 & {$[\mathrm{M}+\mathrm{H}]^{+}$} & $\mathrm{C}_{30} \mathrm{H}_{45} \mathrm{D}_{6}$ & $<0.9$ & $S Q-d_{6}$ \\
\hline 425.3780 & 18.99 & {$\left[(\mathrm{M}+\mathrm{H})-\mathrm{H}_{2} \mathrm{O}\right]^{+}$} & $\mathrm{C}_{30} \mathrm{H}_{49} \mathrm{O}$ & $<1.1$ & $\mathrm{SQ}-\mathrm{OOH}$ \\
\hline 427.3938 & 18.99 & {$[\mathrm{M}+\mathrm{H}]^{+}$} & $\mathrm{C}_{30} \mathrm{H}_{51} \mathrm{O}$ & $<1.4$ & SQ-epoxide \\
\hline 473.3991 & 20.27 & & $\mathrm{C}_{29} \mathrm{H}_{51} \mathrm{O}_{3} \mathrm{~N}_{3}$ & $<1.2$ & $\begin{array}{c}\text { Not a by- } \\
\text { product of SQ }\end{array}$ \\
\hline
\end{tabular}


Cholesterol oxidation products (Figure 4); 25-hydroxycholesterol, 5,6a-epoxycholesterol, and $7 \beta$-hydroxycholesterol have the same monoisotopic mass of $402.3498 \mathrm{Da}\left(\mathrm{C}_{27} \mathrm{H}_{46} \mathrm{O}_{2}\right)$, thus they cannot be distinguished based on the $\left[(\mathrm{M}+\mathrm{H})-\mathrm{H}_{2} \mathrm{O}\right]^{+}\left(\mathrm{m} / z\right.$ 385.3604) ion or the $\left[(\mathrm{M}+\mathrm{H})-2 \mathrm{H}_{2} \mathrm{O}\right]^{+}(\mathrm{m} / \mathrm{z} 367.3498)$ ion. ${ }^{49}$ In addition, the $\left[(\mathrm{M}+\mathrm{H})-2 \mathrm{H}_{2} \mathrm{O}\right]^{+}$ion of cholestane-3 $\beta-5 \alpha-6 \beta$-triol $\left(\mathrm{C}_{27} \mathrm{H}_{48} \mathrm{O}_{3}\right.$, monoisotopic mass $420.3604 \mathrm{Da}$ ) has the same $\mathrm{m} / \mathrm{z}$ ratio; 385.3604 which is isobaric to the aforementioned compounds. ${ }^{49}$ Collision induced dissociation of these compounds in tandem mass spectrometry mainly yields fragments due to loss of water which are nonspecific for characterisation. ${ }^{49} \mathrm{As}$ a result, APCI/HRAM MS alone is not capable of structure elucidation of these compounds, which in turn demands LC based separation. ${ }^{49}$ Such LC separation was not initially planned and authentic standards of these compounds were not analysed as it was beyond the established objectives of this study. Therefore, precursor ions of $\mathrm{m} / \mathrm{z} 367.3498$ and $\mathrm{m} / \mathrm{z} 385.3604$ were collectively attributed to oxidation by-products of cholesterol with no further assigning to individual compounds.

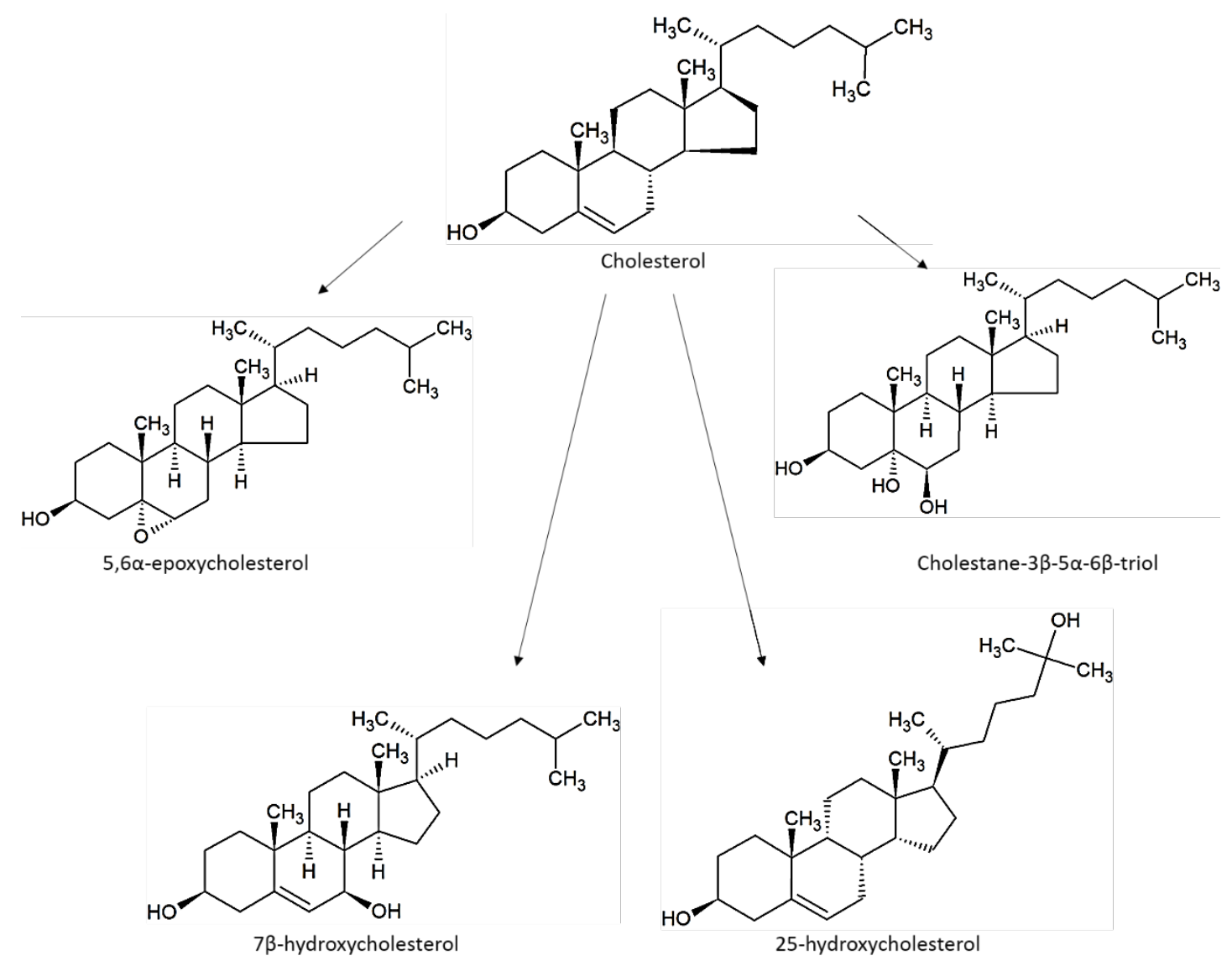

Figure 4. Some oxygenated forms of cholesterol based on Raith et al. ${ }^{49}$ 


\section{Potential trends of transformation by-products over time}

Figure 5 shows the relative quantity of $\mathrm{SQ}-\mathrm{OOH}$ in both fresh and aged ( $\mathrm{t}=1,5$, and 7-day) samples to demonstrate its evolution over time. It also shows the relative amount of SQ present at a given aged sample ( $t=1,5$, and 7-day), which enables comparison of the extent of transformation in relation to the availability of SQ in the sample matrix. Although Mountfort et al. observed an increase in the amount of SQ-OOH between 1 and 5 days of ageing under the light, ${ }^{6}$ this product was hardly detected in all samples aged under light. SQ-OOH was detected in very small amounts in some of the fresh samples mostly from donor D1. SQ-OOH was detected in some of the samples ( $t=5$ and 7-day) aged under dark and water, presumably due to retardation of photo-oxidation in those environments.

In Mountfort and co-workers' study, SQ-OOH were not detected when SQ was no longer available for oxidation. ${ }^{6}$ Intriguingly, in this study, SQ-OOH was not detected in all samples aged under light although SQ was still available for oxidation (at least in small quantities). This contradictory observation could be due to the use of different types of deposits. As opposed to Mountfort's study which used charged deposits, this current study used natural deposits which contain less amount of material compared to charged ones. Hence, the amount of $\mathrm{SQ}-\mathrm{OOH}$ produced in natural deposits could be extremely small, therefore not detected by the mass spectrometer. Other differences in storage conditions (room temperature and humidity) in both studies could also have influenced the variation of the longevity of $\mathrm{SQ}-\mathrm{OOH}$ in deposits. Moreover, further oxidised forms of $\mathrm{SQ}-\mathrm{OOH}$ (i.e., $\mathrm{SQ}-[\mathrm{OOH}]_{n}$ ) were not detected which suggests that SQ-OOH is extremely short-lived and may transform to oxidised products other than $\mathrm{SQ}-[\mathrm{OOH}]_{\mathrm{n}}{ }^{33}$ 

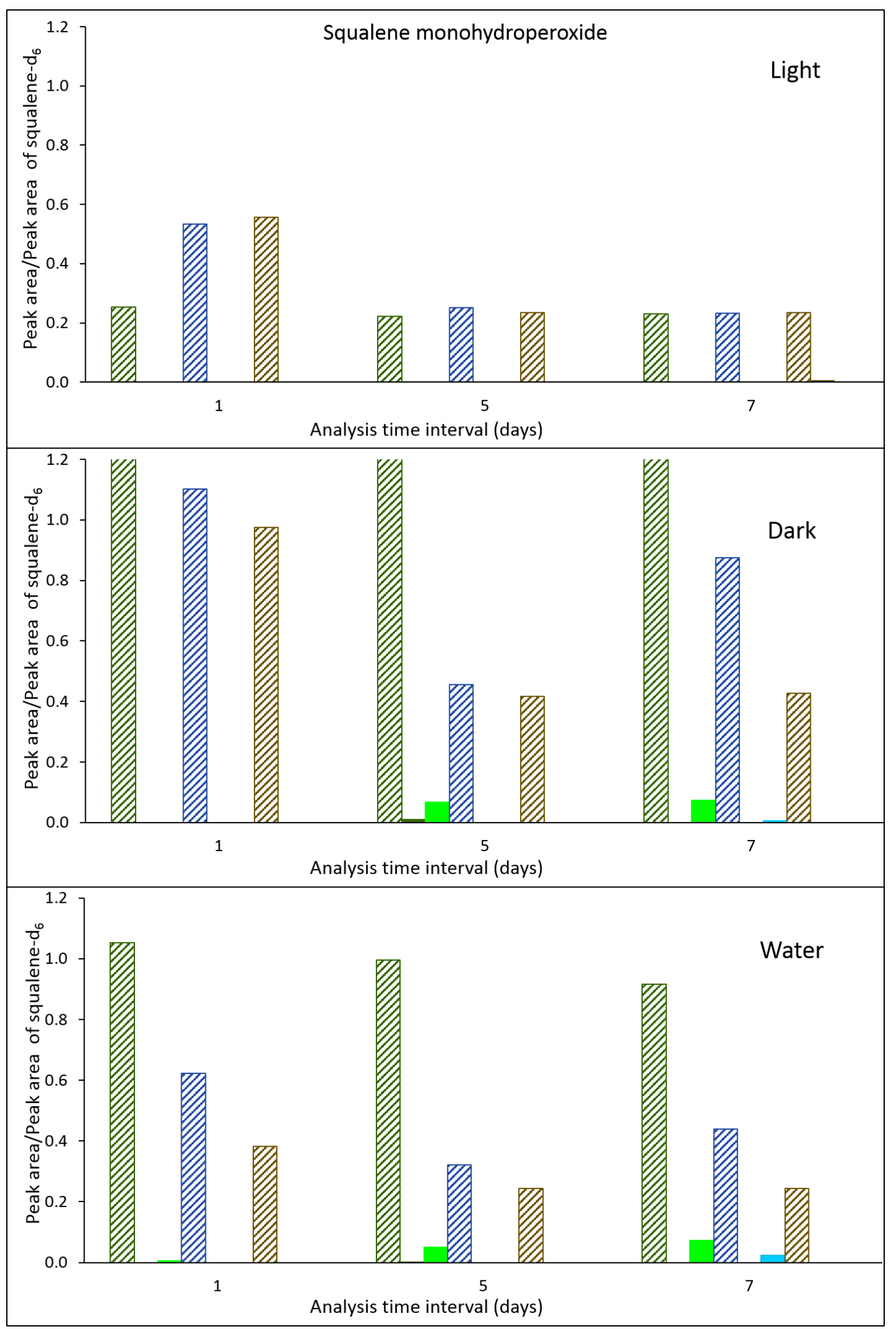

Figure 5. From left to right, relative amounts of squalene in aged samples (patterned filled bars), SQ-OOH in fresh samples $(\mathrm{t}=0$, dark coloured green, blue, and brown bars), and $\mathrm{SQ}-\mathrm{OOH}$ in aged samples ( $\mathrm{t}=\mathrm{t}$, brighter coloured green, blue, and brown bars) of fingermarks from donor D1 (green), D2 (blue), and D4 (brown). Except patterned bars, most of the other bars are not visible as $\mathrm{SQ}-\mathrm{OOH}$ was not detected in these samples. Y-axis of the graphs is not set to illustrate the maximum value of the data set. 
Figure 6 shows the transformation of SQ $\rightarrow$ SQ-epoxide in samples aged under different storage conditions. Unlike SQ-OOH, SQ-epoxide was detected in all fresh samples and a general increasing trend was observed against the initial concentration in samples aged in the dark across all analysis time intervals. However, under light conditions, SQ-epoxide concentration increased only up to 1 day and then reduced markedly in $t=5$ and $t=7$-day samples. Since $S Q$ was more depleted underwater than under dark, SQ-epoxide was also more depleted underwater. Highest amounts of SQ-epoxide in $t=7$-day samples were observed in samples from donor D1 due to considerable amounts of SQ available at those time intervals. Mouzdahir et al. observed a rapid oxidation of SQ under aerobic conditions in seawater caused by the presence of hydroperoxysterols (e.g. SQ-2-ol and SQ-epoxide). ${ }^{52}$ However, such trend was not observed in this study, presumably due to competing behaviours of hydroperoxysterols and other species present in the residue that retard the degradation process.

4,9,13,17-tetramethyl-octadeca-4,8,12,16-tetraenol (TOT) was also identified in all fresh samples (Figure 7), which is in agreement with Girod and Weyermann's study. ${ }^{37} \mathrm{~A}$ similar trend as with SQ-epoxide was noticed for TOT in the samples stored under light. While TOT was decreased from its initial amount in $\mathrm{t}=7$-day samples stored in the dark, it was still rising in $\mathrm{t}=7$-day samples stored underwater. Since squalene was more degraded underwater than in dark, the increasing TOT level underwater suggests that TOT is relatively stable and accumulates under water.

Some of the products detected with precursor ions such as $m / z$ 207.1017, 257.2476, 312.3263, $313.3103,355.2845,359.3156$, and 473.3991 were present only in fresh and/or aged samples of donor D1. As SQ was present in fresh samples from all three donors, these products were regarded as not deriving from SQ (see Supplementary Information Figure S5). 

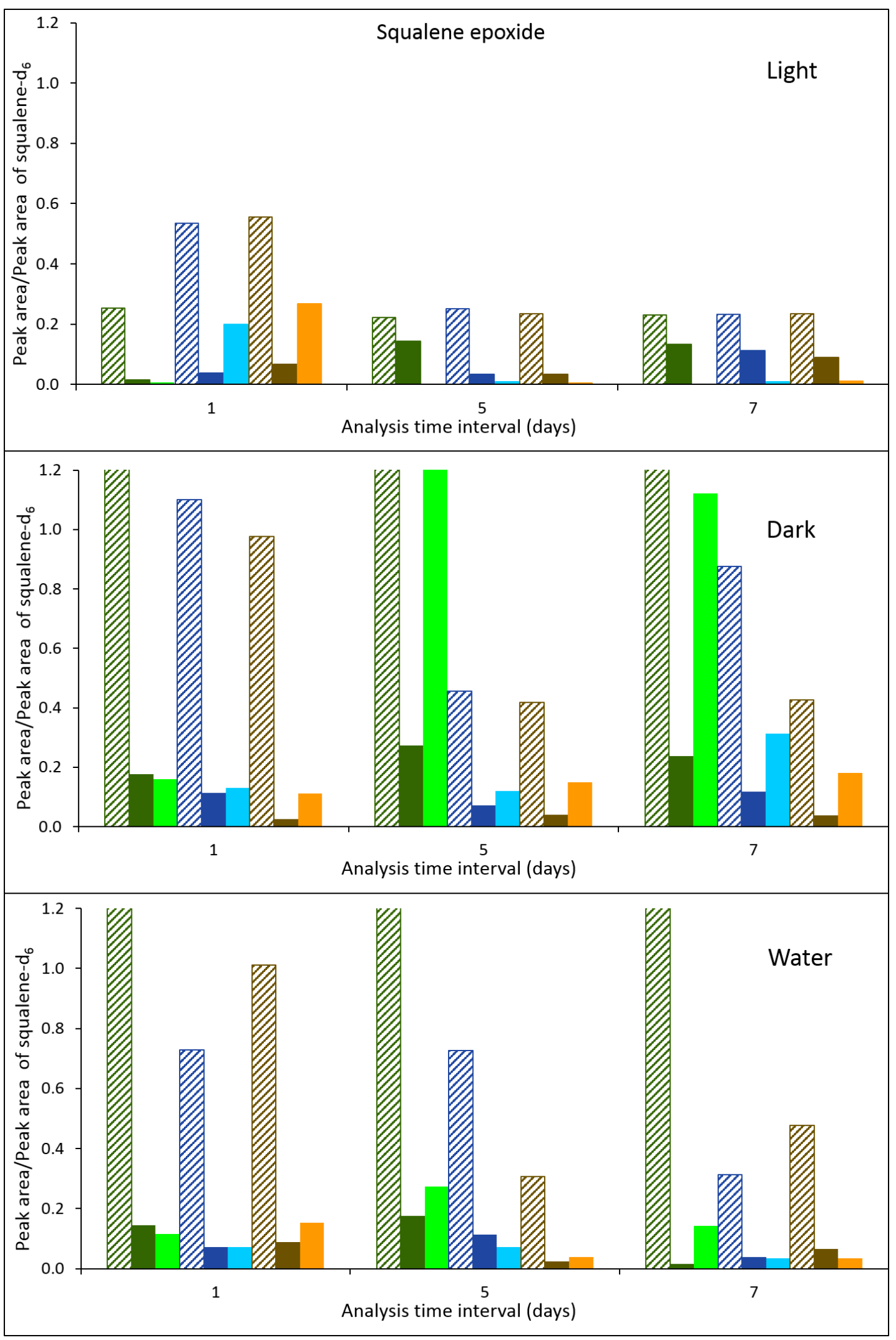

Figure 6. From left to right, relative amounts of squalene in aged samples (patterned filled bars), SQ-epoxide in fresh samples ( $t=0$, dark coloured green, blue and brown bars) and SQ-epoxide in aged samples ( $t=t$, brighter coloured green blue and brown bars) of fingermarks from donor D1 (green), D2 (blue), and D4 (brown). Y-axis of the graphs is not set to illustrate the maximum value of the data set. 

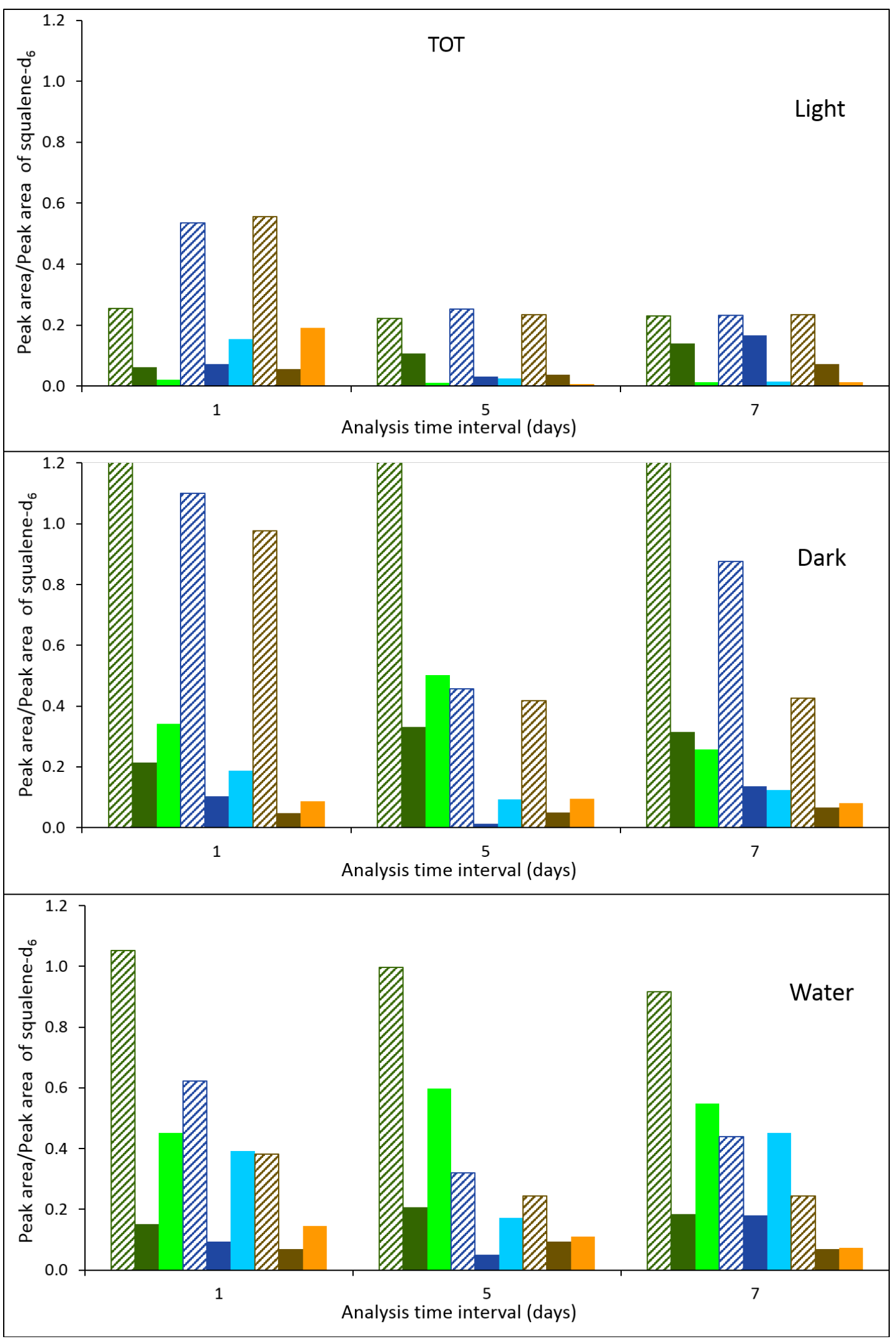

Figure7. From left to right, relative amounts of $S Q$ in aged samples (patterned filled bars), TOT in fresh samples ( $t=0$, dark coloured green, blue and brown bars) and TOT in aged samples ( $t=t$, brighter coloured green blue and brown bars) of fingermarks from donor D1 (green), D2 (blue) and D4 (brown). Y-axis of the graphs is not set to illustrate the maximum value of the data set. 
While cholesterol was identified in samples based on the precursor at $m / z \quad 369.3519$, the corresponding peak was asymmetrical and subjected to tailing (i.e., abnormal increase in the baseline intensity in extracted ion chromatogram for $\mathrm{m} / \mathrm{z} 369.3519$ between c.a. 21 and $24.5 \mathrm{~min}$ ), hence was not used for relative quantification (Supplementary Information Figure S3). However, the peak at $\mathrm{m} / \mathrm{z} 367.3360$ (exact mass $367.3359 \mathrm{Da}$ ), which was tentatively attributed to cholesterol oxidation products by HRAM analysis, had appropriate gaussian shape which enabled further investigations (Supplementary Information Figure S6). Cholesterol oxidation products were identified in all fresh samples, which demonstrated a slow growth with increasing sample age (Figure 8). Interestingly, this was seen with all storage conditions across all analysis time intervals. Cholesterol is another lipid compound that has been identified frequently in fingermark composition, but in relatively low quantities compared to squalene. ${ }^{13,17-18,20,37}$ It was reported that cholesterol in fingermarks degraded at a much slower pace than squalene in a dark environment with no air flow. ${ }^{17}$ This relatively high longevity of cholesterol could be the reason why the amount of its oxidation products were still increasing after 7 days of ageing. Since both SQ-OOH and SQ-epoxide were not detected after ageing for 7 days under light, cholesterol oxidation products could be promising biomarkers for visualisation of aged fingermarks.

Investigations carried out on physical developer (PD) have found that among main lipid classes found in fingermarks, only spots of cholesterol produced significant silver deposition upon treatment with PD. ${ }^{53}$ Due to the fact that cholesterol degrades over time while PD performs effectively on aged deposits, de la Hunty et al. proposed that PD's reactivity towards fingermarks may not be entirely attributed to the presence of cholesterol. ${ }^{5}$ Based on the results of this current study and the research findings and suggestions discussed above, it could be postulated that PD targets both cholesterol and its oxidation by-products. However, since this study was based on non-porous surfaces, further investigations using porous surfaces are required to establish this hypothesis. As emphasised by Cadd et al. in their review on the ageing of fingermark composition, cholesterol decomposition products in fingermarks have never been explored before. ${ }^{54}$ In light of this, investigation of oxidation products of cholesterol could be highly advantageous for improving fingermark detection capabilities. 


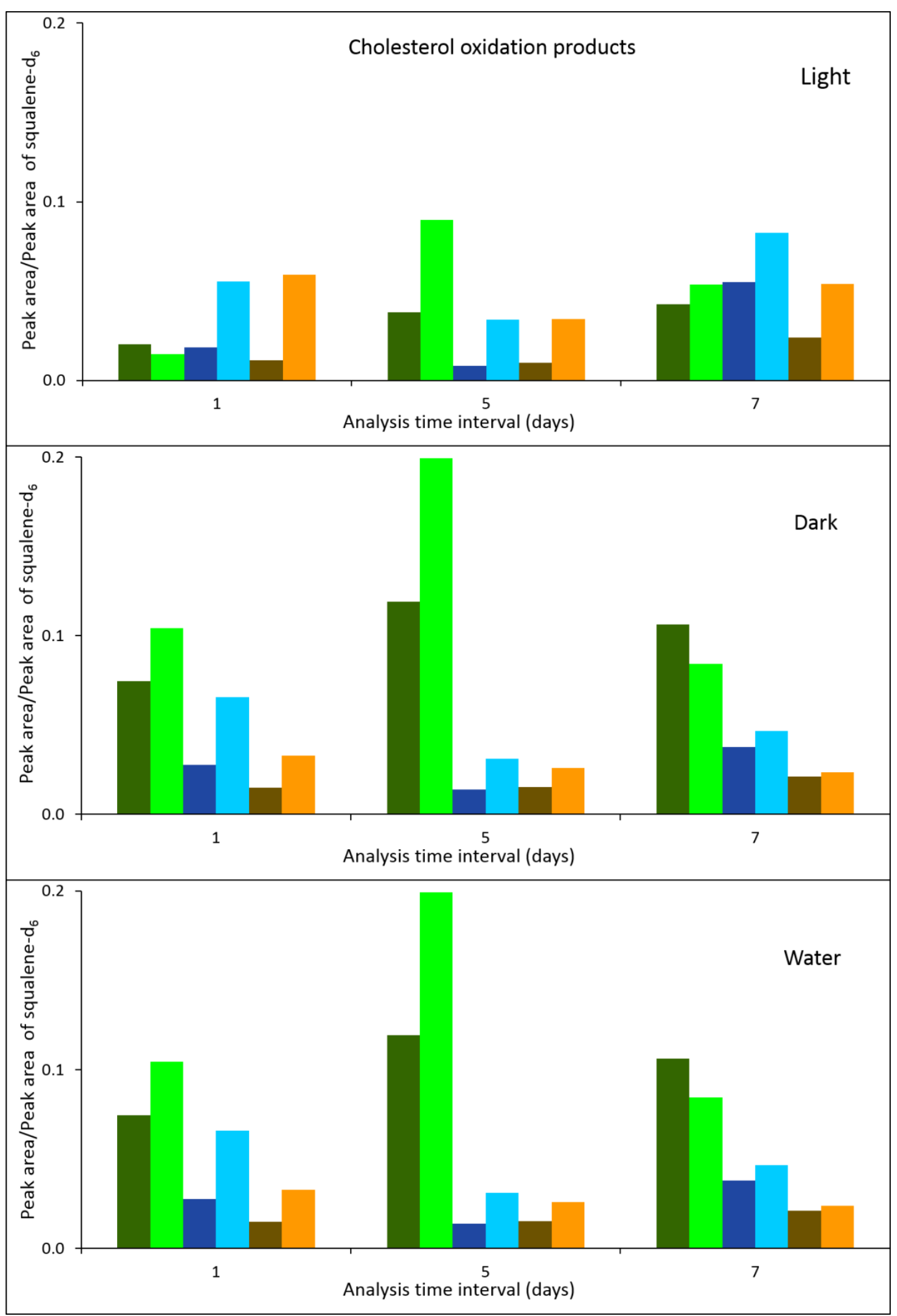

Figure 8. Compositional variation of cholesterol oxidation products in fresh samples ( $t=0$, dark coloured green, blue and brown bars) and in aged samples ( $\mathrm{t}=\mathrm{t}$, brighter coloured green, blue, and brown bars) of fingermarks from donor D1F1 (green), D2M1 (blue) and D11M6 (brown). 
Oxidation of SQ into various products in the APCl ion source was observed (Supplementary Information Figure S7). Base peaks of ions used for the identification of oxidation by-products were seen at two retention times, one being the retention time of SQ $(21.95 \mathrm{~min})$. However, this did not interfere with the analysis since this oxidation occurred post-column (i.e., in the APCI ion source) rather than pre-column and therefore they are chromatographically separated. One practical difficulty faced during this study was the random incidence of carryover of residual SQ. The sample run, in which the results were reported here, had a carryover in blanks which were run after the standards. As the observed peak had the mass to charge ratio and the same retention time of $\mathrm{SQ}$, it was identified as autosampler carryover. ${ }^{55}$ Highly hydrophobic compounds such as SQ are known to absorb/trap in the flow path of the autosampler via ionic interaction with metallic surfaces and hydrophobic interaction with plastic materials due to their tendency to form charged species. ${ }^{55}$ Throughout this study, the injector needle and the injection port was thoroughly washed with ACN before and after each injection. Nevertheless, a small carryover of SQ (c.a. 0.4 ppm) was still detected in the sample blank. The same set of standards and sample blanks were run on a different day using the same instrumental conditions with injecting the sample blank after each standard, and no carryover was detected. Consequently, the carryover could not be quantified and was not subtracted from the samples.

Mountfort et al. suggested that oxidation by-products of SQ such as $\mathrm{SQ}-[\mathrm{OOH}]_{4}$ and $\mathrm{SQ}-[\mathrm{OOH}]_{5}$ could make suitable targets for novel fingermark detection techniques due to their durability in solution. ${ }^{6}$ Nakagawa et al. further proposed that isomers of SQ-OOH such as 6-SQ-OOH, 11-SQ-OOH, and 2-SQ-OOH may present such targets. ${ }^{30}$ Nonetheless, results of this study propose that none of these products would be present in fingermark deposits recovered from real-life situations due to their short lifetime or non-existence in such matrices.

However, the results suggest that SQ-epoxide and oxidation by-products of cholesterol may offer suitable functionalities with enough longevity that could be targeted by novel techniques for visualisation of aged deposits. Oil red $\mathrm{O}$ and Nile red are lipid stains that are currently being used to detect fingermarks where dye molecules interact with the labile fraction of lipids (non-polar or less polar) such as fatty acids and triglycerides. ${ }^{56}$ Upon exposure to air, fatty acids and triglycerides oxidise rapidly hence, these techniques offer unreliable performance on aged deposits. ${ }^{56}$ To this end, probing more polar robust fraction of fingermark lipids would be advantageous. ${ }^{56}$ Biochemical imaging of polar lipids by staining with a luminescent rhenium complex was successfully demonstrated recently. ${ }^{57}$ Since SQ-epoxide and the oxidation products of cholesterol identified in this study are polar biomolecules, ${ }^{58}$ perhaps these novel staining methods could be adapted as innovative techniques for visualisation of aged fingermarks. 


\section{Conclusion}

Transformation of squalene over time in fingermarks deposited on non-porous surfaces was studied under different storage conditions by ultra-high-performance liquid chromatography-high resolution accurate mass Orbitrap ${ }^{\mathrm{TM}}$ mass spectrometry. Complications of assessing fingermark compositional variation using multiple samples with varying initial compositions were demonstrated and an alternate approach was proposed which successfully identified trends of degradation of squalene over time.

A rapid oxidation of squalene was observed in all storage conditions while some of its oxidation by-products were relatively stable under dark and aquatic environments. Though oxidation by-products were not individually identified, some oxidation by-products of cholesterol were collectively identified that displayed prolonged persistence under any storage condition tested. These oxidation by-products, therefore, hold great potential as biomarkers for targeted visualisation of aged deposits and should be further explored. In addition, the significance of using natural deposits in time-course studies of fingermark composition was demonstrated, as otherwise research outcomes may be overstated and inefficacious.

The results discussed in this study illuminate key areas of fingermark research; investigating compositional variation over time while addressing issues arising due to intra-donor variation and underwater fingermark chemistry, which have not been explored in detail previously. While the inherent difficulties associated with fingermark research may never be eliminated, investigation of strategies to evade them within a realistic context may result in significant improvements in current detection capabilities.

\section{Acknowledgments}

The authors would like to acknowledge the contribution of an Australian Government Research Training Program Scholarship for BND. The authors would like to thank all the fingermark donors for their cooperation. The authors declare no competing financial interest. This study has been approved by the Curtin University Human Research Ethics Committee (Approval Number RDSE-02-15). 


\section{References}

1. Wargacki, S. P.; Lewis, L. A.; Dadmun, M. D., Understanding the chemistry of the development of latent fingerprints by superglue fuming. Journal of Forensic Sciences 2007, 52 (5), 1057-1062.

2. Wargacki, S. P.; Lewis, L. A.; Dadmun, M. D., Enhancing the quality of aged latent fingerprints developed by superglue fuming: loss and replenishment of initiator. Journal of Forensic Sciences 2008, 53 (5), 1138-1144.

3. Czekanski, P.; Fasola, M.; Allison, J., A mechanistic model for the superglue fuming of latent fingerprints. Journal of Forensic Sciences 2006, 51 (6), 1323-1328.

4. de la Hunty, M.; Moret, S.; Chadwick, S.; Lennard, C.; Spindler, X.; Roux, C., Understanding physical developer (PD): Part I-IS PD targeting lipids? Forensic Science International 2015, 257, 481487.

5. $\quad$ de la Hunty, M.; Moret, S.; Chadwick, S.; Lennard, C.; Spindler, X.; Roux, C., Understanding Physical Developer (PD): Part II-IS PD targeting eccrine constituents? Forensic Science International 2015, 257, 488-495.

6. Mountfort, K. A.; Bronstein, H.; Archer, N.; Jickells, S. M., Identification of Oxidation Products of Squalene in Solution and in Latent Fingerprints by ESI-MS and LC/APCI-MS. Analytical Chemistry 2007, 79 (7), 2650-2657.

7. Pleik, S.; Spengler, B.; Schäfer, T.; Urbach, D.; Luhn, S.; Kirsch, D., Fatty Acid Structure and Degradation Analysis in Fingerprint Residues. Journal of The American Society for Mass Spectrometry 2016, 27 (9), 1565-1574.

8. Richmond-Aylor, A.; Bell, S.; Callery, P.; Morris, K., Thermal Degradation Analysis of Amino Acids in Fingerprint Residue by Pyrolysis GC-MS to Develop New Latent Fingerprint Developing Reagents*. Journal of Forensic Sciences 2007, 52 (2), 380-382.

9. De Paoli, G., Lewis Sr, S., Schuette, E., Lewis, L., Connatser, R., Farkas, T., Photo-and ThermalDegradation Studies of Select Eccrine Fingerprint Constituents. Journal of Forensic Sciences 2010, 55 (4), 962-969.

10. Wolstenholme, R., Bradshaw, R., Clench, M., Francese, S., Study of latent fingermarks by matrix-assisted laser desorption/ionisation mass spectrometry imaging of endogenous lipids. Rapid Communications in Mass Spectrometry 2009, 23 (19), 3031-3039.

11. Spindler, X.; Hofstetter, O.; McDonagh, A. M.; Roux, C.; Lennard, C., Enhancement of latent fingermarks on non-porous surfaces using anti-l-amino acid antibodies conjugated to gold nanoparticles. Chem. Commun. 2011, 47 (19), 5602-5604.

12. Ma, R.; Shimmon, R.; McDonagh, A.; Maynard, P.; Lennard, C.; Roux, C., Fingermark detection on non-porous and semi-porous surfaces using $\mathrm{YVO} 4: \mathrm{Er}, \mathrm{Yb}$ luminescent upconverting particles. Forensic Science International 2012, 217 (1), e23-e26.

13. Archer, N. E.; Charles, Y.; Elliott, J. A.; Jickells, S., Changes in the lipid composition of latent fingerprint residue with time after deposition on a surface. Forensic Science International 2005, 154 (2), 224-239.

14. Frick, A.; Chidlow, G.; Goodpaster, J.; Lewis, S.; van Bronswijk, W., Monitoring compositional changes of the lipid fraction of fingermark residues deposited on paper during storage. Forensic Chemistry 2016, 2, 29-36.

15. Mong, G. M.; Petersen, C.; Clauss, T. Advanced fingerprint analysis project fingerprint constituents; Pacific Northwest National Lab., Richland, WA (US): 1999.

16. Croxton, R. S.; Baron, M. G.; Butler, D.; Kent, T.; Sears, V. G., Variation in amino acid and lipid composition of latent fingerprints. Forensic Science International 2010, 199 (1), 93-102.

17. Weyermann, C.; Roux, C.; Champod, C., Initial results on the composition of fingerprints and its evolution as a function of time by GC/MS analysis. Journal of Forensic Sciences 2011, 56 (1), 102108. 
18. Koenig, A.; Girod, A.; Weyermann, C., Identification of Wax Esters in Latent Print Residues by Gas Chromatography-Mass Spectrometry and Their Potential Use as Aging Parameters. Journal of Forensic Identification 2011, 61 (6), 606-631.

19. Girod, A.; Spyratou, A.; Holmes, D.; Weyermann, C., Aging of target lipid parameters in fingermark residue using GC/MS: effects of influence factors and perspectives for dating purposes. Science \& Justice 2016, 56 (3), 165-180.

20. Frick, A.; Chidlow, G.; Lewis, S.; Van Bronswijk, W., Investigations into the initial composition of latent fingermark lipids by gas chromatography-mass spectrometry. Forensic Science International 2015, 254, 133-147.

21. Langdon, R. G.; Bloch, K., The utilization of squalene in the biosynthesis of cholesterol. Journal of Biological Chemistry 1953, 200 (1), 135-144.

22. Camera, E.; Ottaviani, M.; Picardo, M., Squalene chemistry and biology. In Lipids and Skin Health, Springer: 2015; pp 185-198.

23. Kellum, R. E., Human sebaceous gland lipids: Analysis by thin-layer chromatography. Archives of Dermatology 1967, 95 (2), 218-220.

24. Downing, D. T.; Strauss, J. S.; Pochi, P. E., Variability in the chemical composition of human skin surface lipids. Journal of Investigative Dermatology 1969, 53 (5), 322-327.

25. Greene, R. S.; Downing, D. T.; Pochi, P. E.; Strauss, J. S., Anatomical variation in the amount and composition of human skin surface lipid. Journal of Investigative Dermatology 1970, 54 (3), $240-$ 247.

26. Picardo, M.; Zompetta, C.; De Luca, C.; Cirone, M.; Faggioni, A.; Nazzaro-Porro, M.; Passi, S.; Prota, G., Role of skin surface lipids in UV-induced epidermal cell changes. Archives of Dermatological Research 1991, 283 (3), 191-197.

27. Nicolaides, N., Skin lipids: their biochemical uniqueness. Science 1974, 186 (4158), 19-26.

28. Rabasco Alvarez, A. M.; González Rodríguez, M. L., Lipids in pharmaceutical and cosmetic preparations. Grasas y Aceites 2000, 51 (1-2), 74-96.

29. Kohno, Y.; Egawa, Y.; Itoh, S.; Nagaoka, S.-i.; Takahashi, M.; Mukai, K., Kinetic study of quenching reaction of singlet oxygen and scavenging reaction of free radical by squalene in $\mathrm{n}$-butanol. Biochimica et Biophysica Acta (BBA)-Lipids and Lipid Metabolism 1995, 1256 (1), 52-56.

30. Nakagawa, K.; Ibusuki, D.; Suzuki, Y.; Yamashita, S.; Higuchi, O.; Oikawa, S.; Miyazawa, T., Iontrap tandem mass spectrometric analysis of squalene monohydroperoxide isomers in sunlight-exposed human skin. Journal of Lipid Research 2007, 48 (12), 2779-2787.

31. Mudiyanselage, S. E.; Elsner, P.; Thiele, J. J.; Hamburger, M., Ultraviolet A induces generation of squalene monohydroperoxide isomers in human sebum and skin surface lipids in vitro and in vivo. Journal of Investigative Dermatology 2003, 120 (6), 915-922.

32. Ohsawa, K.; Watanabe, T.; Matsukawa, R.; Yoshimura, Y.; Imaeda, K., The possible role of squalene and its peroxide of the sebum in the occurrence of sunburn and protection from the damage caused by UV irradiation. The Journal of Toxicological Sciences 1984, 9 (2), 151-159.

33. Luca, C.; Picardo, M.; Brcathnach, A.; Passi, S., Lipoperoxidase activity of Pityrosporum: characterisation of by-products and possible rôle in pityriasis versicolor. Experimental Dermatology 1996, 5 (1), 49-56.

34. Dennis, K. J.; Shibamoto, T., Production of Malonaldehyde from Squalene, A Major Skin Surface Lipid, During UV-Irradiation. Photochemistry and Photobiology 1989, 49 (5), 711-716.

35. Yeo, H.; Shibamoto, T., Formation of formaldehyde and malonaldehyde by photooxidation of squalene. Lipids 1992, 27 (1), 50-53.

36. Petrick, L.; Dubowski, Y., Heterogeneous oxidation of squalene film by ozone under various indoor conditions. Indoor Air 2009, 19 (5), 381-391.

37. Girod, A.; Weyermann, C., Lipid composition of fingermark residue and donor classification using GC/MS. Forensic Science International 2014, 238, 68-82.

38. Nazzaro-Porro, M.; Passi, S.; Picardo, M.; Mercantini, R.; Breathnach, A. S., Lipoxygenase activity of Pityrosporum in vitro and in vivo. Journal of Investigative Dermatology 1986, 87 (1), 108112. 
39. Kohno, Y.; Sakamoto, O.; Tomita, K.; Horii, I.; Miyazawa, T., Determination of human skin surface lipid peroxides by chemiluminescence-HPLC. Journal of Japan Oil Chemists' Society 1991, 40 (9), 715-718.

40. Chiba, K.; Sone, T.; Kawakami, K.; Onoue, M., Skin roughness and wrinkle formation induced by repeated application of squalenemonohydroperoxide to the hairless mouse. Experimental Dermatology 1999, 8 (6), 471-479.

41. Gheshlaghi, R.; Scharer, J.; Moo-Young, M.; Douglas, P., Application of statistical design for the optimization of amino acid separation by reverse-phase HPLC. Analytical Biochemistry 2008, 383 (1), 93-102.

42. Dorakumbura, B. N.; Busetti, F.; Lewis, S. W., Investigations into sampling approaches for chemical analysis of latent fingermark residue. Forensic Chemistry 2019, 100166.

43. Dorakumbura, B. N.; Boseley, R. E.; Becker, T.; Martin, D. E.; Richter, A.; Tobin, M. J.; van Bronswjik, W.; Vongsvivut, J.; Hackett, M. J.; Lewis, S. W., Revealing the spatial distribution of chemical species within latent fingermarks using vibrational spectroscopy. Analyst 2018, 143 (17), 4027-4039.

44. Daéid, N. N.; Carter, S.; Laing, K., Comparison of vacuum metal deposition and powder suspension for recovery of fingerprints on wetted nonporous surfaces. Journal of Forensic Identification 2008, 58 (5), 600.

45. Trapecar, M., Fingerprint recovery from wet transparent foil. Egyptian Journal of Forensic Sciences 2012, 2 (4), 126-130.

46. Rohatgi, R.; Kapoor, A. K., Development of latent fingerprints on wet non-porous surfaces with SPR based on basic fuchsin dye. Egyptian Journal of Forensic Science 2016, 6.

47. Bumbrah, G. S., Small particle reagent (SPR) method for detection of latent fingermarks: A review. Egyptian Journal of Forensic Sciences 2016, 6 (4), 328-332.

48. Cuce, P.; Polimeni, G.; Lazzaro, A. P.; Fulvio, G. D., Small particle reagents technique can help to point out wet latent finger prints. Forensic Science International (Suppl) 2004, 146.

49. Raith, K.; Brenner, C.; Farwanah, H.; Müller, G.; Eder, K.; Neubert, R. H., A new LC/APCI-MS method for the determination of cholesterol oxidation products in food. Journal of Chromatography $A$ 2005, 1067 (1), 207-211.

50. Newton, S.; Carter, C. F.; Pearson, C. M.; de C Alves, L.; Lange, H.; Thansandote, P.; Ley, S. V., Accelerating spirocyclic polyketide synthesis using flow chemistry. Angewandte Chemie International Edition 2014, 53 (19), 4915-4920.

51. Hori, S.; Murai, M.; Takai, K., Rhenium-Catalyzed anti-Markovnikov Addition Reaction of Methanetricarboxylates to Unactivated Terminal Acetylenes. Journal of the American Chemical Society 2015, $137(4), 1452-1457$.

52. Mouzdahir, A.; Bakkas, S.; Rontani, J.-F., Aerobic and anaerobic abiotic oxidation of squalene in the presence of hydroperoxides. Chemosphere 2001, 44 (4), 771-777.

53. Anon, What is the oldest fingerprint that you have developed? In Fingerprint Development and Imaging Update, Home Office Police Scientific Development Branch. Publication No. 26/2003: 2003.

54. Cadd, S.; Islam, M.; Manson, P.; Bleay, S., Fingerprint composition and aging: A literature review. Science \& Justice 2015, 55 (4), 219-238.

55. Hughes, N. C.; Wong, E. Y.; Fan, J.; Bajaj, N., Determination of carryover and contamination for mass spectrometry-based chromatographic assays. The American Association of Pharmaceutical Scientists Journal 2007, 9 (3), E353-E360.

56. Ramotowski, R. S., Lipid Reagents. In Lee and Gaensslen's Advances in Fingerprint Technology, 3rd ed.; CRC Press: 2012; pp 83-96.

57. Bader, C.; Carter, E.; Safitri, A.; Simpson, P.; Wright, P.; Stagni, S.; Massi, M.; Lay, P.; Brooks, D.; Plush, S., Unprecedented staining of polar lipids by a luminescent rhenium complex revealed by FTIR microspectroscopy in adipocytes. Molecular BioSystems 2016, 12 (7), 2064-2068.

58. Schmarr, H.-G.; Gross, H. B.; Shibamoto, T., Analysis of polar cholesterol oxidation products: evaluation of a new method involving transesterification, solid phase extraction, and gas chromatography. Journal of Agricultural and Food Chemistry 1996, 44 (2), 512-517. 
Page 30 of 30 
Analysis of squalene and its transformation by-products in latent fingermarks by ultrahigh-performance liquid chromatography-high resolution accurate mass Orbitrap ${ }^{\mathrm{TM}}$ mass spectrometry

Buddhika N. Dorakumbura ${ }^{a, b \neq *}$, Francesco Busetti ${ }^{c}$ and Simon W. Lewis ${ }^{a, b}$

${ }^{a}$ School of Molecular and Life Sciences, Curtin University, GPO Box U1987, Perth, Western Australia, 6845, Australia.

${ }^{b}$ Curtin Institute of Functional Molecules and Interfaces, Curtin University, GPO Box U1987, Perth, Western Australia, 6845, Australia.

' School of Science, Edith Cowan University, 270 Joondalup Drive, Joondalup, Western Australia, 6027, Australia.

${ }^{\ddagger}$ Present address: ChemCentre, PO Box 1250, Bentley, Western Australia, 6983, Australia.

*Author for correspondence (E-mail: buddhidk1013@gmail.com)

Electronic Supplementary Information

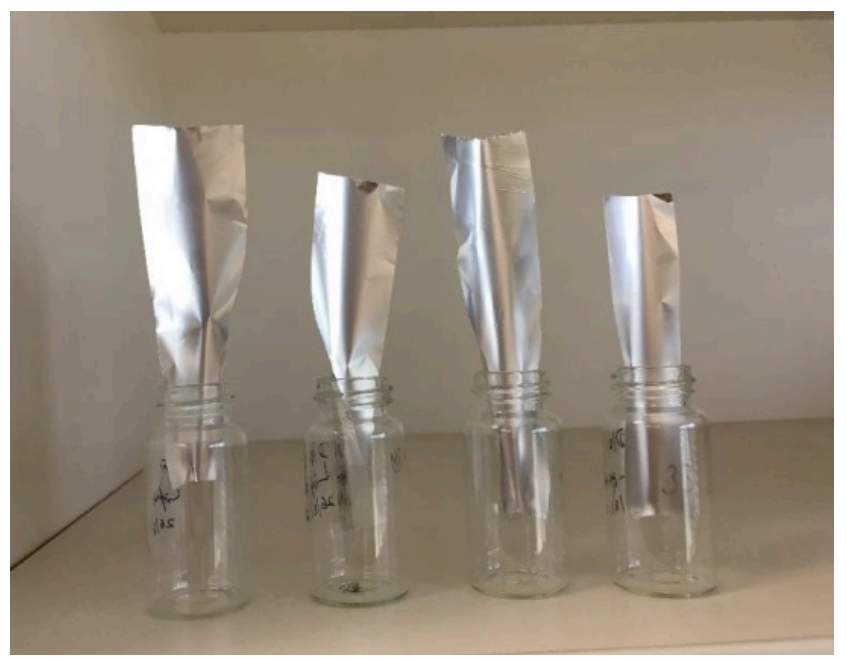

Figure S1. Storage of fingermark samples in open vials under light conditions over a 7-day period. 


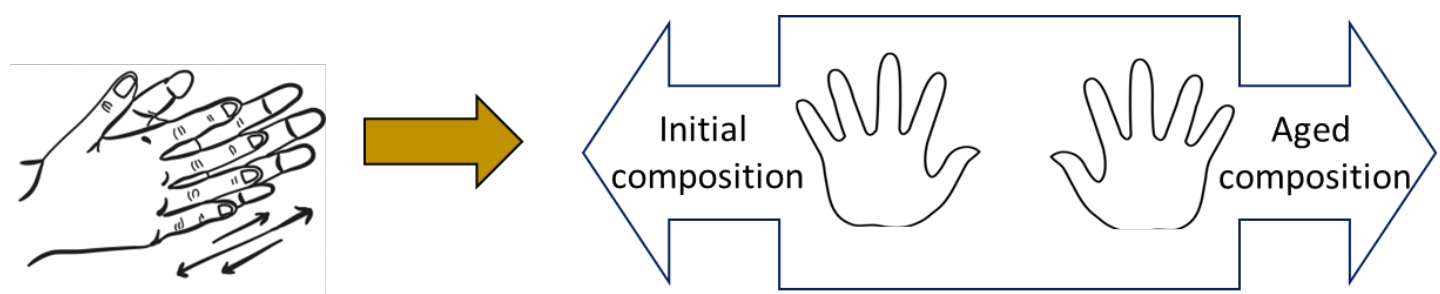

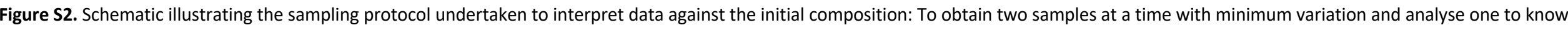

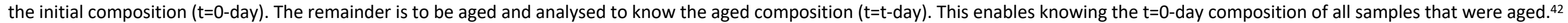




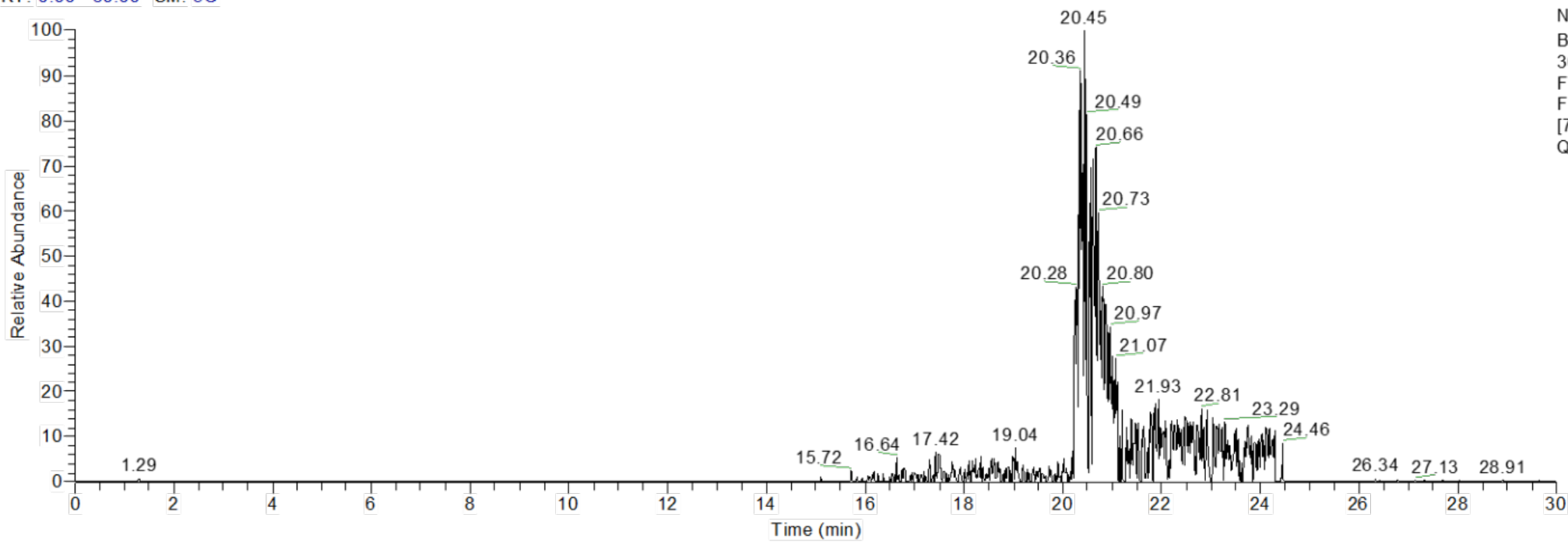

NL: $3.68 \mathrm{E} 6$

ase Peak $\mathrm{m} / \mathrm{z}=$

69.3496-369.3518 F

Full $\mathrm{m}$

0000] MS

QE_2017_002486

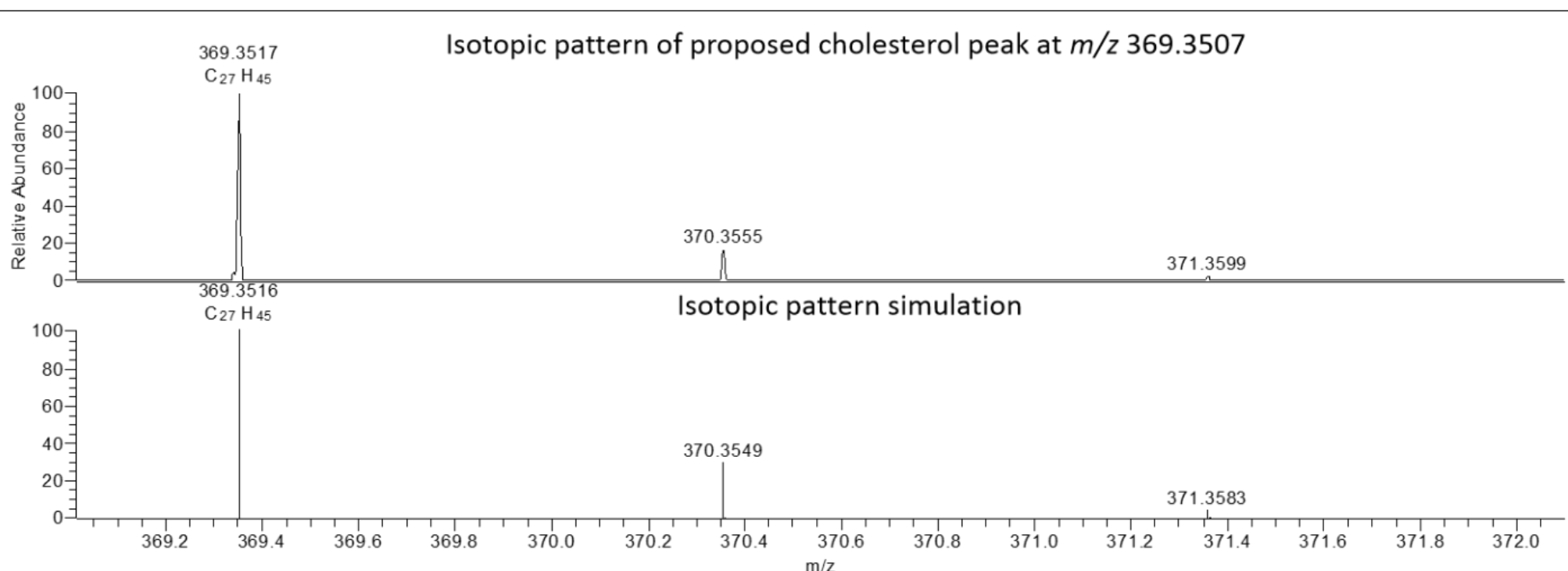

NL:

QE_2017_002486\#793 0 RT: $20.42 \mathrm{AV}: 1 \mathrm{~T}$. FTMS + p APCl corona Full $\mathrm{ms}$

[70.0000-1000.0000]

\section{$\mathrm{NL}:$}

$\mathrm{C}_{27} \mathrm{H}_{45}$ :

$\mathrm{C}_{27} 7 \mathrm{H}_{45}$

Figure S3. Extracted ion chromatogram of m/z 369.3507 and isotopic pattern comparison between peak proposed to be cholesterol and simulation using Xcalibur software. 


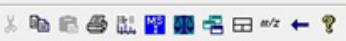

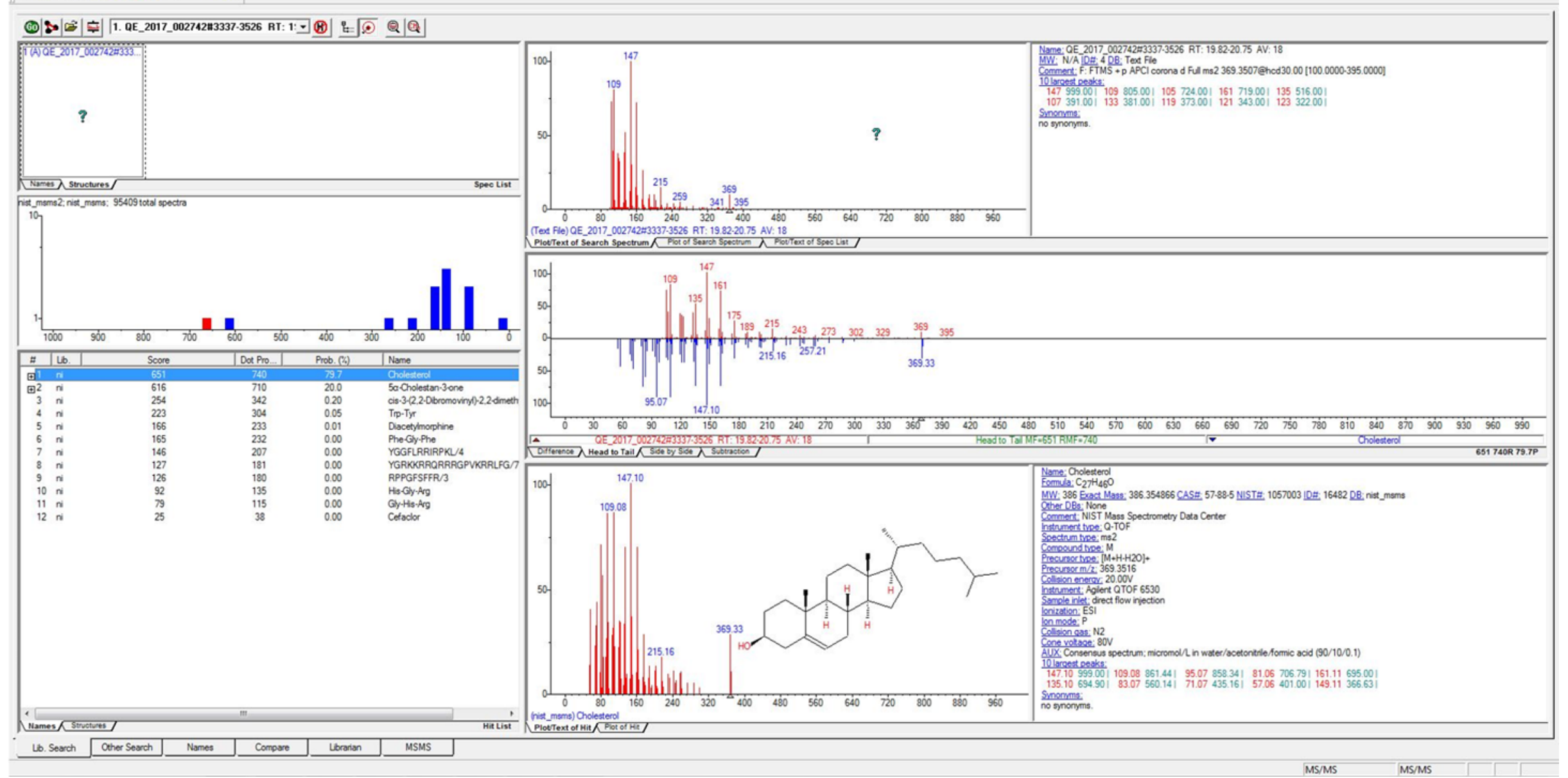

Figure S4. NIST MS/MS library comparison of the proposed cholesterol peak at m/z 369.3507 


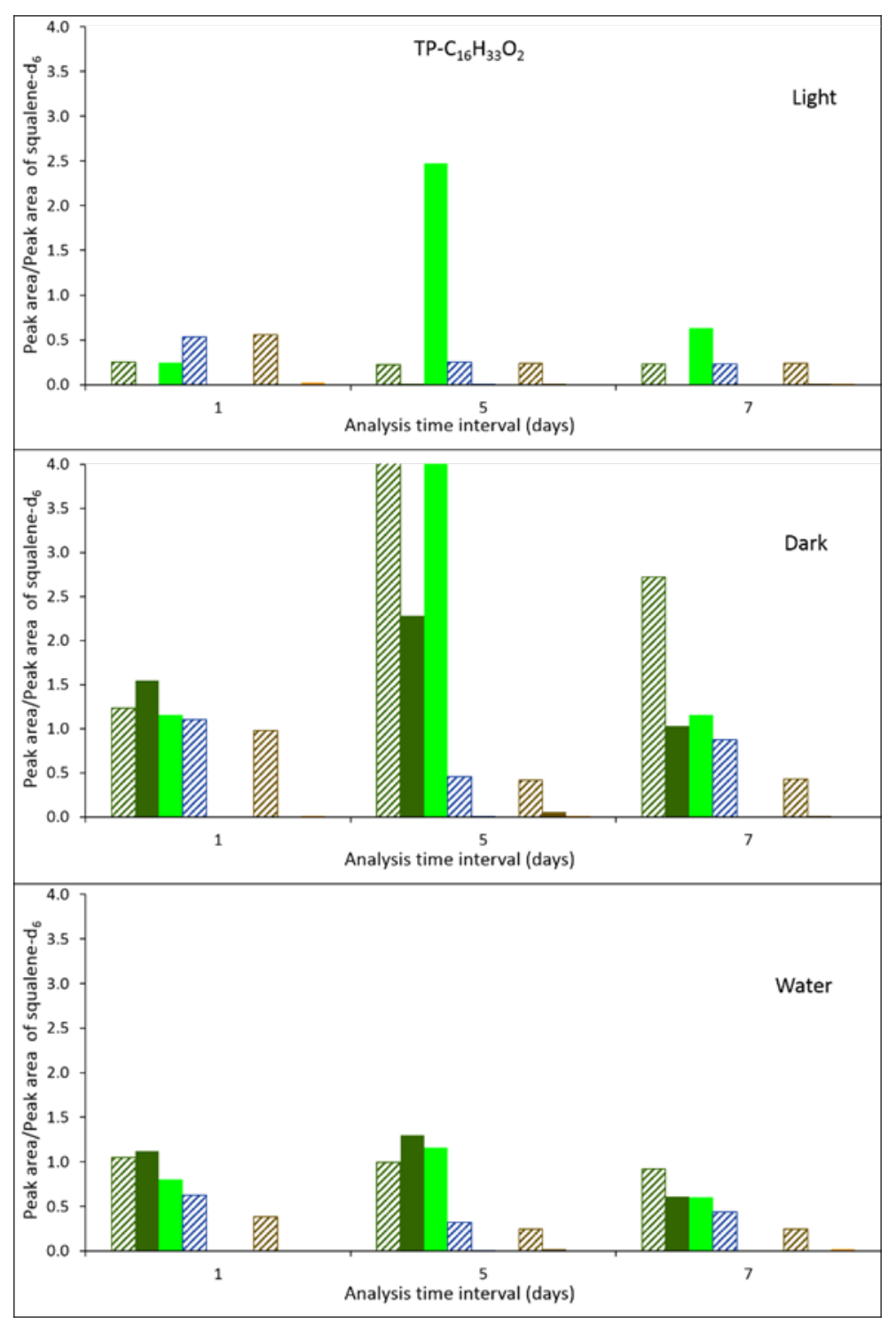

Figure S5. Compositional variation of the precursor ion $\mathrm{C}_{16} \mathrm{H}_{33} \mathrm{O}_{2}$ (filled bars) in relation to the availability of SQ in the aged samples (patterned filled bars). The relative amount of the ion in fresh

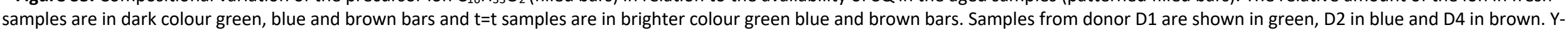
axis of the graphs is not set to illustrate the maximum value of the data set. 

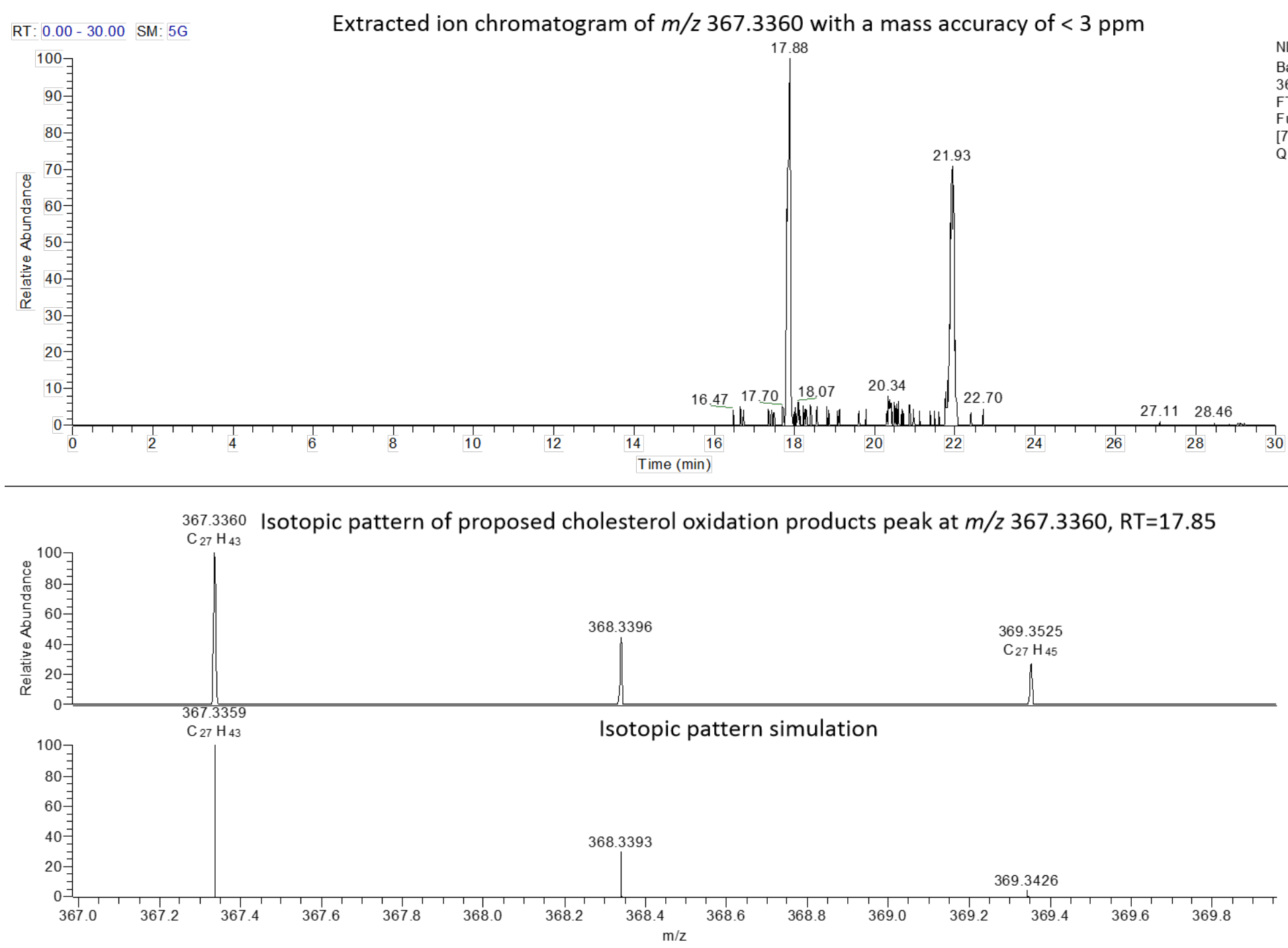

NL:

QE_2017_002486\#692

5 RT: 17.85 AV: 1 T:

FTMS + p APCl corona

[70.0000-1000.0000]

NL:

$\mathrm{C}_{27} \mathrm{H}_{43}$ :

pa Chrg 1

Figure S6. Extracted ion chromatogram of $\mathrm{m} / \mathrm{z} 367.3360$ and isotopic pattern comparison between peak proposed to be cholesterol oxidation products and simulation using Xcalibur software. 
RT: $0.00-30.00$ SM: $5 \mathrm{G}$

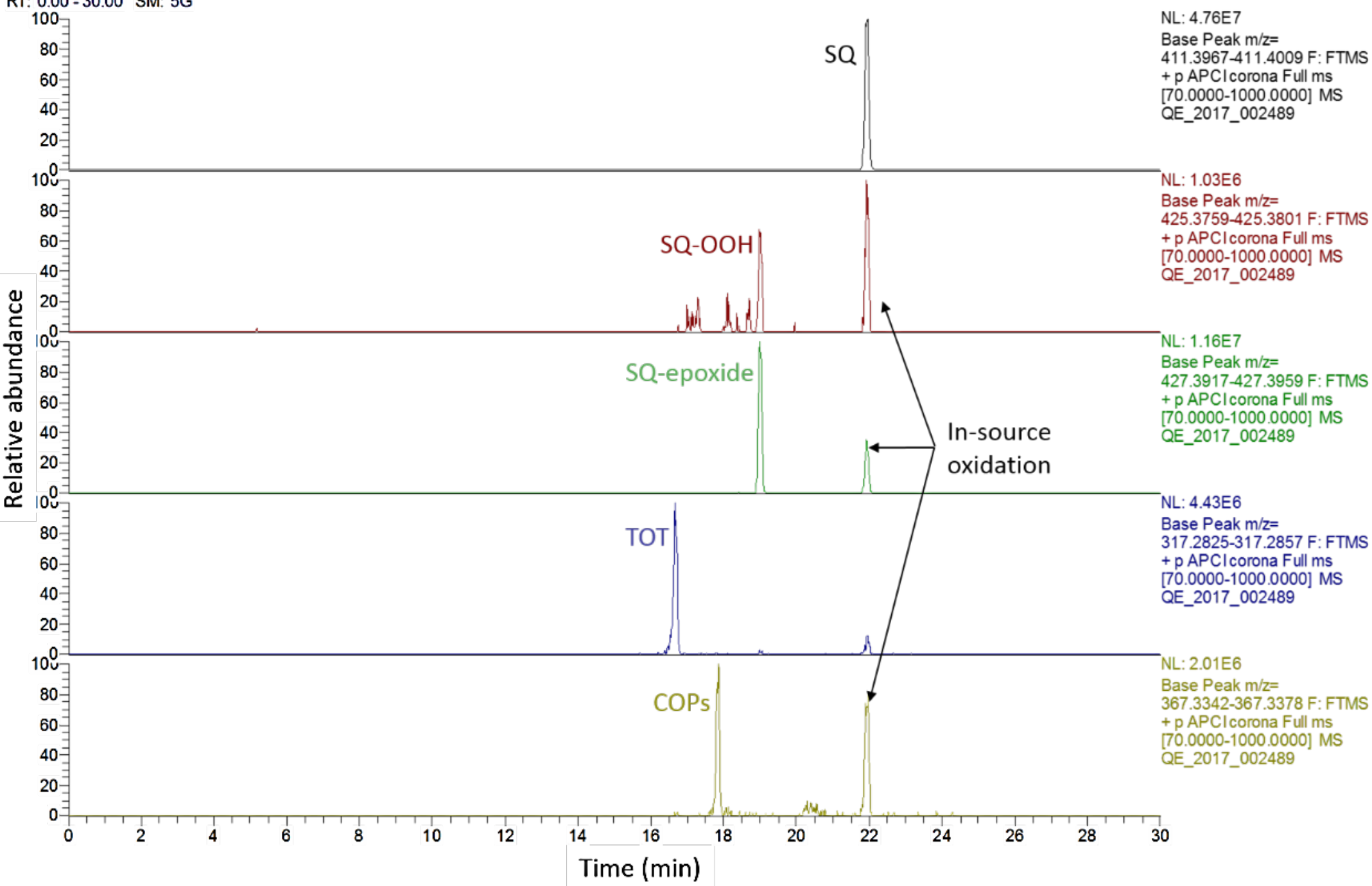

Figure S7. Formation of the oxidation products in the $\mathrm{APCl}$ ion source. 